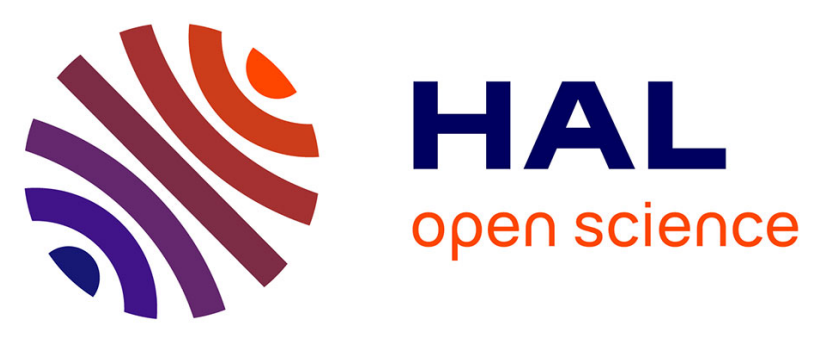

\title{
Impact of long-term storage of various redox-sensitive supported nanocomposites on their application in removal of dyes from wastewater: mechanisms delineation through spectroscopic investigations
}

Nitin Khandelwal, Ekta Tiwari, Nisha Singh, Remi Marsac, Thorsten Schäfer, Fazel Abdolahpur Monikh, Gopala Krishna Darbha

\section{To cite this version:}

Nitin Khandelwal, Ekta Tiwari, Nisha Singh, Remi Marsac, Thorsten Schäfer, et al.. Impact of long-term storage of various redox-sensitive supported nanocomposites on their application in removal of dyes from wastewater: mechanisms delineation through spectroscopic investigations. Journal of Hazardous Materials, 2021, 401, pp.123375. 10.1016/j.jhazmat.2020.123375 . insu-02893076

\section{HAL Id: insu-02893076 \\ https://hal-insu.archives-ouvertes.fr/insu-02893076}

Submitted on 8 Jul 2020

HAL is a multi-disciplinary open access archive for the deposit and dissemination of scientific research documents, whether they are published or not. The documents may come from teaching and research institutions in France or abroad, or from public or private research centers.
L'archive ouverte pluridisciplinaire HAL, est destinée au dépôt et à la diffusion de documents scientifiques de niveau recherche, publiés ou non, émanant des établissements d'enseignement et de recherche français ou étrangers, des laboratoires publics ou privés. 


\section{Journal Pre-proof}

Impact of long-term storage of various redox-sensitive supported nanocomposites on their application in removal of dyes from wastewater:

mechanisms delineation through spectroscopic investigations

Nitin Khandelwal<ce:contributor-role $>$ Writing- orignial draft) (Data curation) (Investigation)<ce:contributor-role>Visualisation), Ekta Tiwari (Investigation) (Data curation)<ce:contributor-role $>$ Writing-review and editing), Nisha Singh (Investigation) (Data curation)<ce:contributor-role>Writing-review and editing), Remi Marsac (Supervision)<ce:contributor-role $>$ Writing-review and editing), Thorsten Schäfer (Supervision)<ce:contributor-role> Writing-review and editing), Fazel Abdolahpur Monikh (Data curation)<ce:contributor-role>Writing-review and editing), Gopala Krishna Darbha<ce:contributor-role $>$ Writing-review and editing) (Resources) (Supervision) (Project administration) (Funding acquisition)

PII: $\quad$ S0304-3894(20)31364-9

DOI: $\quad$ https://doi.org/10.1016/j.jhazmat.2020.123375

Reference: HAZMAT 123375

To appear in: Journal of Hazardous Materials

Received Date: 23 April 2020

Revised Date: $\quad 12$ June 2020

Accepted Date: $\quad 1$ July 2020

Please cite this article as: Khandelwal N, Tiwari E, Singh N, Marsac R, Schäfer T, Monikh FA, Darbha GK, Impact of long-term storage of various redox-sensitive supported nanocomposites on their application in removal of dyes from wastewater: mechanisms 
delineation through spectroscopic investigations, Journal of Hazardous Materials (2020), doi: https://doi.org/10.1016/j.jhazmat.2020.123375

This is a PDF file of an article that has undergone enhancements after acceptance, such as the addition of a cover page and metadata, and formatting for readability, but it is not yet the definitive version of record. This version will undergo additional copyediting, typesetting and review before it is published in its final form, but we are providing this version to give early visibility of the article. Please note that, during the production process, errors may be discovered which could affect the content, and all legal disclaimers that apply to the journal pertain.

(C) 2020 Published by Elsevier. 
Impact of long-term storage of various redox-sensitive supported nanocomposites on their application in removal of dyes from wastewater: mechanisms delineation through spectroscopic investigations

Nitin Khandelwala ${ }^{a}$, Ekta Tiwari ${ }^{\mathrm{a}}$, Nisha Singh ${ }^{\mathrm{a}}$, Remi Marsac ${ }^{\mathrm{b}}$, Thorsten Schäfer ${ }^{\mathrm{c}}$, Fazel Abdolahpur Monikh ${ }^{\text {, Gopala Krishna Darbha, }}$,

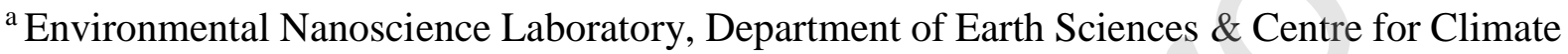
and Environmental Studies, Indian Institute of Science Education and Research Kolkata, Mohanpur, West Bengal, India- 741246

${ }^{\mathrm{b}}$ Geosciences Rennes - UMR CNRS, Universite De Rennes 1, Campus De Beaulieu, CS74205, 35042 Rennes Cedex, France

'Institute of Geosciences, Applied Geology, Friedrich-Schiller-Universitat Jena, Burgweg 11, D-07749, Jena, Germany

${ }^{\mathrm{d}}$ Institute of Environmental Sciences (CML), Leiden University, P.O. Box 9518, 2300 RA Leiden, Netherlands

*Corresponding author: Gopala Krishna Darbha, Email- gkdarbha@gmail.com, gkdarbha80@yahoo.com Tel: (+91)- 9849626082 


\section{Graphical Abstract}

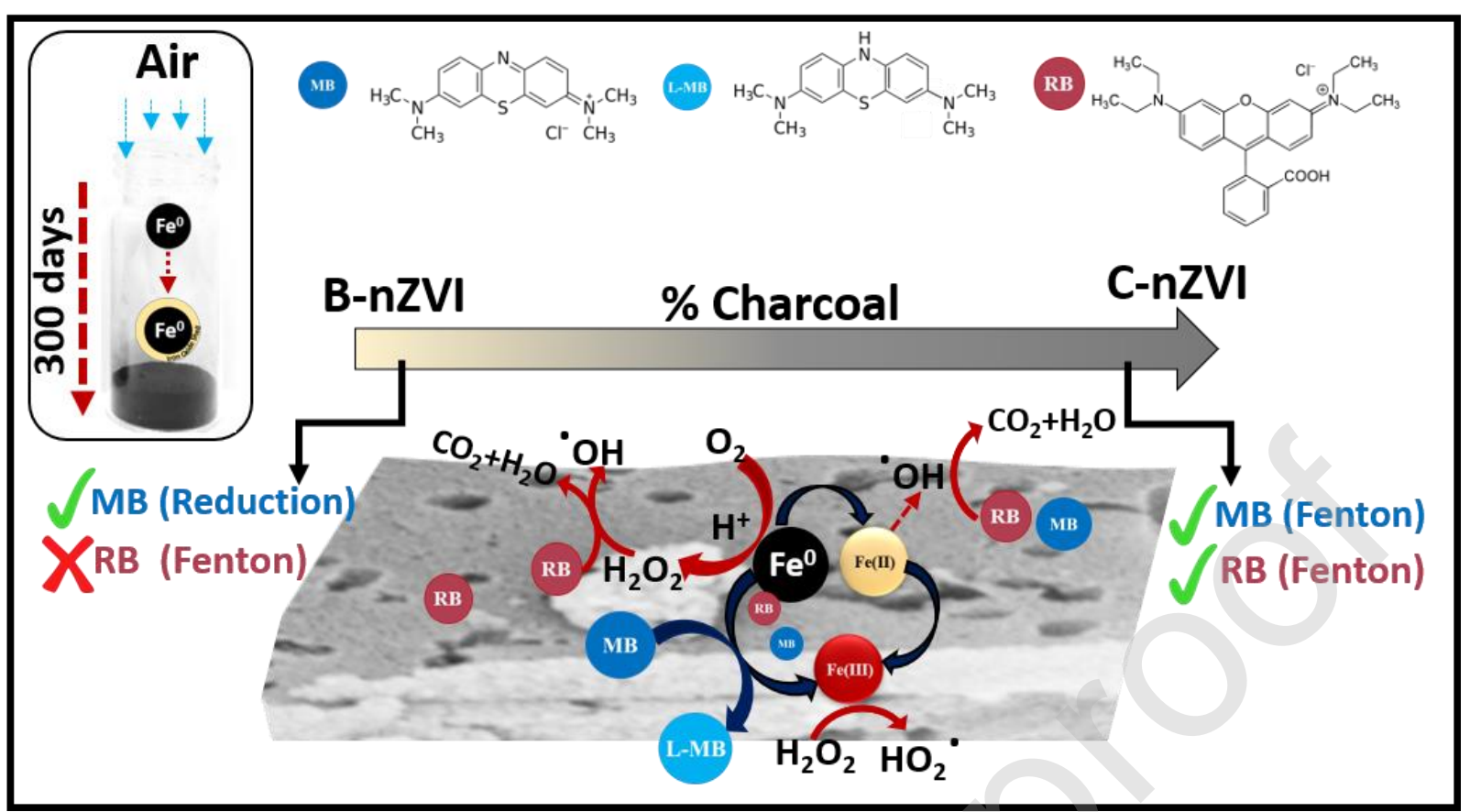

\section{Highlights}

- Dyes removal mechanisms of redox particles were dependent on supporting surfaces

- Redox nanocomposites compared for dyes removal, pre/ post 300 days of air exposure

- IR analysis show reduction/organic degradation as major dye degradation mechanisms

- C-nZVI and novel BC-1/3-nZVI were found efficient dye adsorbents with minimal aging

- Recovery of $<5 \%$ for $\mathrm{MB}$ and $<40 \%$ for $\mathrm{RB}$ confirms sorption irreversibility or degradation 


\section{Abstract}

For the prevention of freshwater reservoirs from contamination through industrial effluents, eco-friendly adsorbents with minimal aging impact are required. Here, redox-sensitive nanoscale zero-valent iron(nZVI) particles were supported on four different surfaces with varying bentonite(B)/charcoal(C) ratio to mimic layered and porous surfaces. Different dyes, i.e. rhodamine- $\mathrm{B}(\mathrm{RB})$ and methylene blue $(\mathrm{MB})$ were reacted with redox-sensitive supported nZVI composites, and degradation mechanisms were delineated using FT-IR spectroscopic analysis of reaction precipitates. A 300-day exposure to open-air was provided to the composites to comparatively evaluate the impact of aging on their reactivity for dyes in wastewater.

Results interpret that dyes removal was a combination of different interfacial chemical processes, i.e., reduction or organic degradation probably through Fenton like processes, along with sorption. These mechanisms were found to be surface dependent, i.e., nZVI on charcoal enriched porous surfaces, degrade dyes through organic degradation while on layered clay surfaces, MB gets removed through reduction with limited and slower RB removal. Nanocomposites show a minimal impact of aging with removal capacities $>100 \mathrm{mg} / \mathrm{g}$ for BC1/3-nZVI and C-nZVI for MB and 50-75 mg/g for RB with significant removal in wastewater. Overall, the study concludes C-nZVI and novel BC-1/3-nZVI as two efficient dye adsorbents with minimal aging impact. 


\section{Introduction}

Safe drinking water is a common need of every human being and is of crucial importance for the sustainment of a healthy ecosystem. But rapid industrialization and constant release of toxic waste are limiting the available freshwater resources.

Among these wastes, dyes are of serious concern due to their associated toxicity, stability and limited biodegradability [1]. Their widespread usage in textiles, pulp mills, leather industries, paper printing, plastics manufacturing, etc., and further release into the environment contributes to their aquatic pollution $[1,2]$. For instance, a low concentration of dyes $(>1 \mathrm{mg} / \mathrm{L})$ can result in colored water, imparting adverse effects on aquatic life by preventing light penetration [3]. Moreover, dyes can easily interact with cell membranes to enter inside the cells and can induce toxicity [4]. Further, the human impact of some dyes range from eyes burning, skin irritation and if ingested, nausea, vomiting, and diarrhea [5], while some dyes like Rhodamine-B are proved carcinogens [6].

Plenty of methods have been explored for the remediation of dye-contaminated water including bioremediation [7-9], adsorption [10, 11], coagulation/flocculation [12], ozonation [13], advanced oxidation [14-17], liquid-liquid extraction [18] and membrane filtration [19, 20], etc. Bolisetty et al. has provided a comparative description of these different remediation techniques [21]. Briefly, several methods face some critical issues, like- coagulation/flocculation results in non-reusable chemicals, coagulants, and flocculants resulting in high volume sludge generation [22]. Ion-exchange involves expensive setup and poses regeneration issues, bioremediation requires a longer duration, while others have high operating/ maintenance cost or may generate secondary contamination $[21,22]$. Therefore, considering economic viability, environmental friendliness, scalability, and effectiveness, adsorption proves to be the only 
suitable technique $[23,24]$ as it has simplified setup, low developing and maintenance costs, target specificity, regeneration capability and reusability [25].

Advancement in the field of sorption had resulted in the development of redox-sensitive nanoparticles like- zero-valent metal nanoparticles, i.e., iron, aluminum [26], selenium [27]and copper [28], etc., reduced metal oxides like- magnetite $\left(\mathrm{Fe}_{3} \mathrm{O}_{4}\right)$ [29], and reduced graphene oxide [30], etc. Along with adsorption of dyes on the surface, these redox-sensitive nanoparticles can participate in electron transfer at the interface, which may lead to pollutants degradation or precipitation via different chemisorption mechanisms [31]. For example, once the pollutants come at the interface of adsorbent and water, redox-sensitive particles release the electrons and get oxidized. Adsorbate molecules can uptake these released electrons and get reduced. Simultaneously, these reduced products can get coprecipitated on the generated outer shell of metal oxy-hydroxides. On the other hand, in the presence of dissolved oxygen, the released electron can form free radicals and degrade pollutants through Fenton like reactions as provided below in equations 1-7 [32].

$$
\begin{aligned}
& \mathrm{M}^{0}+\mathrm{O}_{2}+2 \mathrm{H}^{+} \rightarrow \mathrm{M}^{2+}+\mathrm{H}_{2} \mathrm{O}_{2} \\
& \mathrm{M}^{2+}+\mathrm{H}_{2} \mathrm{O}_{2} \rightarrow \mathrm{M}^{3+}+\mathrm{OH}+\mathrm{OH}^{-} \\
& 2 \mathrm{M}^{3+}+\mathrm{M}^{0} \rightarrow 3 \mathrm{M}^{2+} \\
& \mathrm{M}^{0}+2 \mathrm{H}^{+} \rightarrow \mathrm{M}^{2+}+\mathrm{H}_{2} \\
& \mathrm{M}^{2+}+\mathrm{O}_{2} \rightarrow \mathrm{M}^{3+}+\mathrm{O}_{2}^{-} \\
& \mathrm{O}_{2}^{--}+\mathrm{H}^{+} \leftrightarrow \mathrm{HO}_{2}^{\cdot} \\
& \mathrm{HO}_{2}^{\cdot}+\mathrm{HO}_{2} \rightarrow \mathrm{H}_{2} \mathrm{O}_{2}+\mathrm{O}_{2}
\end{aligned}
$$


But the preservation of their redox state in the natural environment is a critical challenge because most of these particles get easily aggregated and oxidized in natural environmental conditions [33], which not only limits their reactivity but also leads to secondary contamination in many cases [34]. Supporting these particles on various natural or synthetic surfaces likeclays, biochar, zeolites, activated carbon, graphene, etc. can be helpful in preserving the original redox state of nanoparticles and maintain their reactivity as shown in earlier studies [35-40]. For example, Peng et al. have reported 95\% removal of RB with humic acid-modified $\mathrm{Fe}_{3} \mathrm{O}_{4}$ particles at an optimized $\mathrm{pH}$ [41]. Similarly, Liang et al. showed no RB removal with bare nZVI, while $99.9 \%$ of RB can be removed by using nZVI-g- $\mathrm{C}_{3} \mathrm{~N}_{4}$ composite [42]. Jiao et al. have used reduced graphene oxide (RGO)/chitosan/silver nanoparticle composites and showed that without UV light irradiation, the composite could remove a very high amount of MB (q= $166.9 \mathrm{mg} / \mathrm{g})$ but limited RB $(29.9 \mathrm{mg} / \mathrm{g})$ from water solutions. Dada et al. utilized bentonite supported nZVI particles and showed complete RB removal in a controlled environment with $\mathrm{pH}=3$ and 120 minutes of contact time [43]. In another study, Guo et al. showed $83.3 \%$ removal of RB with polyaniline-nZVI composite which was only $11.15 \%$ with bare $\mathrm{nZVI}$ after $2 \mathrm{hr}$ contact time with an initial $\mathrm{RB}$ concentration of $0.02 \mathrm{mmol} / \mathrm{L}(\mathrm{pH}=6.50)$ [44]. It is worth to mention that, apart from preventing the oxidation of the redox-sensitive nanoparticles, these supporting surfaces can induce a variation in contaminant removal mechanisms. For instance, Li et al. have utilized biochar supported nZVI nanocomposite for degradation of trichloroethylene (TCE)where, superoxide radical, $\mathrm{Fe}^{0}$ mediated singlet oxygen and oxygen-containing group (i.e., $\mathrm{C}=\mathrm{O}$ ) were found responsible mechanisms for $\mathrm{TCE}$ dechlorination [45]. Whereas Lie et al. have shown adsorption and reduction as dominant mechanisms for 1,1,2-TCA removal by polymer entrapped nZVI [46]. Conclusively, the role of supporting surfaces in preserving redox properties and enhancing the reactivity of composite is well reported. However, there is limited knowledge available on supporting surface-mediated 
variation in contamination degradation or removal mechanisms of redox-sensitive nanoparticles for dyes.

Similarly, to the best of our knowledge, no study exists which explores such a long term (300 days) air exposure aging impact on the reactivity of surface supported redox-sensitive particles, particularly for dyes. Few studies report the effect of solution-based nZVI aging and its impact on the removal of different contaminants. For example, Calderon et al. have shown the release of adsorbed metals from bare nZVI caused by aging, which produced a $\mathrm{pH}$ decrease and nZVI surface crystallization [47]. Further, Dong et al. have studied short (5-15 days) and long (3090 days) term aging impact on the reactivity of carboxymethyl cellulose (CMC)-coated zerovalent iron in static water over a period of 90 days suggesting that $\mathrm{CMC}$ coating slows down the aging rate [48]. Therefore, long term air exposure and its impact on the reactivity of surface supported redox-sensitive composite is still unexplored [49]. Most of the dye removal studies have been conducted using redox-sensitive supported nanocomposites are limited to controlled conditions, but the dye-contaminated water from industrial effluents is a complex aqueous matrix containing other interfering ions and organic matter which can impact the dye removal efficiency of nanocomposites and hence it is essential to check the reactivity of the composites in wastewater[50].

With reference to the above, there exist significant scientific gaps in the field of redox-sensitive supported nanocomposites for dye removal, which are as follows-

(i) After air exposure (oxidizing conditions), for how long the reactivity of the surface supported redox-sensitive particles can be retained for dyes?

(ii) Can the supporting surfaces impact the interaction or contaminant removal mechanisms of redox-sensitive particles for different dyes? 
(iii) What is the impact of complex aqueous matrices like- wastewater on the reactivity of fresh and aged composites for different dyes?

In current work, to understand and explore these scientific questions, nZVI particles were selected to mimic redox-sensitive nature because of its adsorptive nature and electron transferring capability [51]. Most of the surfaces used to support nZVI particles either have layered structure like- clays, graphene and LDHs etc. [52, 53] or porous nature like- Charcoal, Biochar, porous polymers etc. [54], or it can be a combination of both like- Zeolites [55, 56]. Therefore, to mimic different eco-friendly surfaces, Bentonite clay (B) as layered [57] and charcoal (C) as porous material [58-60] were used. To combine both the properties, novel mixtures having different Bentonite/Charcoal ratios were also prepared and utilized to support nZVI particles.

For the first time, to understand the impact of long term air exposure on the reactivity of redoxsensitive nanocomposites, these synthesized B/C/BC-nZVI composites were characterized and exposed to the normal air environment for 300 days and then comparatively evaluated for the removal of methylene blue $(\mathrm{MB})$ and rhodamine $\mathrm{B}(\mathrm{RB})$ dyes from both distilled and synthetic wastewater (SWW) solutions. Composites were also investigated for desorption and recovery of dyes after reaction using distilled water and organic solvent, i.e., ethanol. To delineate different removal mechanisms and the effect of supporting surface compositions, the FT-IR spectra of various reaction precipitates, before and after washing, were also recorded and analyzed. Removal kinetics and non-linear isotherm modeling were also performed to get insights about the removal mechanisms.

\section{Materials and methods}

\subsection{Materials and chemicals}


For the synthesis of nZVI supported with bentonite clay (B), charcoal (C) and bentonitecharcoal mixture (BC), extra pure Bentonite clay was obtained from Loba Chemie Pvt. Ltd., India with the composition (wt $\%$ )- $54.9 \% \mathrm{SiO}_{2}, 19.2 \% \mathrm{Al}_{2} \mathrm{O}_{3}, 8.3 \% \mathrm{Fe}_{2} \mathrm{O}_{3}, 1.99 \% \mathrm{MgO}, 0.17 \%$ $\mathrm{CaO}, 1 \% \mathrm{~K}_{2} \mathrm{O}$ and $3.79 \% \mathrm{Na}_{2} \mathrm{O}$ [61]. Activated charcoal, $\mathrm{FeCl}_{3} \cdot 6 \mathrm{H}_{2} \mathrm{O}$, ethanol and $\mathrm{NaBH}_{4}$ were purchased from Merck, India and used without further purification. For the preparation of synthetic wastewater (method adapted from Cherdchoo et al. [62]), the following chemicals were obtained from Merck- Sucrose, Sodium acetate, $\mathrm{NH}_{4} \mathrm{Cl}, \mathrm{MgCl}_{2}, \mathrm{CaCl}_{2} .2 \mathrm{H}_{2} \mathrm{O}, \mathrm{NaHCO}_{3}$, $\mathrm{Na}_{2} \mathrm{HPO}_{4}$, and $\mathrm{KH}_{2} \mathrm{PO}_{4}$. $18.2 \mathrm{M} \Omega \mathrm{cm}$ Milli-Q water (DIW) was used to prepare all solutions. Methylene blue was procured from Merck, India, while Rhodamine B was purchased from Sigma-Aldrich, USA.

\subsection{Synthesis of various nZVI composites}

$\mathrm{NaBH}_{4}$ reduction method is the easiest way to synthesize nZVI particles but can result in surface oxidation without a supporting surface $[63,64]$. The supporting surfaces help in controlling iron oxidation and aggregation, which results in the preserved reactivity of the composites [40]. Considering the above factors, four different composites of nZVI with varying bentonite $(\mathrm{B})$ and charcoal $(\mathrm{C})$ ratios i.e. 1:0 (B-nZVI), 1:1 (BC-1/2-nZVI), 1:3 (BC-1/3-nZVI) and 0:1 (C-nZVI) were synthesized. For B-nZVI and C-nZVI, a one-step bottom-up approach (aqueous chemical reduction) was used. Briefly supporting material $(\mathrm{B} / \mathrm{C})$ and $\mathrm{FeCl}_{3} \cdot 6 \mathrm{H}_{2} \mathrm{O}$ has been taken in 1:1 (Fe:B/C) mass ratio in ethanol-water interfacial solution (4:1 by volume). For proper homogenization, suspensions were sonicated (45 minutes) and vigorously shaken (30 minutes). Iron was reduced on different surfaces by adding $\mathrm{NaBH}_{4}(1 \mathrm{M})$ at $4.5 \mathrm{ml} / \mathrm{min}$ flow rate under constant vigorous stirring till 20 minutes after addition to ensure complete reduction. Then the particles were filtered, washed with ethanol, dried, and stored before utilization [65]. 
In the case of various BC supported nZVI composites, 2 step process was used. Firstly, bentonite and charcoal powders were mixed in different ratios i.e. bentonite: charcoal $=1: 1(\mathrm{BC}$ 1/2) and 1:3 (BC-1/3) in aqueous solution and sonicated for $1 \mathrm{hr}$ followed by intense shaking for $72 \mathrm{hrs}$ for well mixing. These BC composites were oven-dried, powdered and used for BCnZVI synthesis by following a similar procedure in the second step, as stated above [65].

All dried composites were characterized and utilized for RB and MB removal. Further, these composites were kept in HDPE bottles in a normal air environment and aged for 300 days to confirm the efficiency of composite for $\mathrm{RB}$ and $\mathrm{MB}$ removal and of supporting material for the prevention of iron oxidation.

\subsection{Characterization of various nanocomposites}

Information about surface morphology, shape, and size of the particles was obtained through scanning and transmission electron micrographs using FESEM (Carl Zeiss SUPRA- 55VP) and UHR-FEG-TEM (JEOL, JEM 2100 F). Powder X-ray diffractograms were obtained using benchtop powder X-ray diffractometer (Rigaku mini flex, Japan) with $\mathrm{Cu} \mathrm{K \alpha}=1.54059 \AA$ radiation at $40 \mathrm{kV} / 15 \mathrm{~mA}$. The scanning range of $5^{\circ}$ to $65^{\circ} 2 \theta$ at $5^{\circ} 2 \theta / \mathrm{min}$ scanning rate, was used. Thermoscie Nicolet iS5 coupled with iD1 transmission accessory was used to perform Fourier transform infrared (FTIR) spectroscopy studies by making KBr pellets to obtain the information about surface functional groups and to ensure various interaction mechanisms as well. Zeta potentials for all the composites in SWW and pHPZC (point of zero charge) in DIW were measured using the dynamic light scattering technique (Malvern Zetasizer ZS-90) and an associated accessory, i.e., MPT-2 multi-purpose $\mathrm{pH}$ Autotitrator. The residual RB and MB concentrations in the solutions were analyzed using UV-Visible spectrophotometer (Evolution 201, Thermo-fisher scientific) at $554 \mathrm{~nm}$ (RB) and $664 \mathrm{~nm}$ (MB), wavelengths, respectively.

\subsection{Sorption experiments and control: Batch method}


The batch method was used to evaluate the MB and RB sorption capacities of fresh and aged nanocomposites. To obtain the information about adsorbed and degraded fraction of dyes, 20 $\mathrm{mg}$ of the composite was added to $20 \mathrm{ml}, 20 \mathrm{mg} / \mathrm{L}$ solutions of $\mathrm{MB}$ and $\mathrm{RB}(\mathrm{pH}=6.4)$ and shaken at $25^{\circ} \mathrm{C}$ for $6 \mathrm{~h}$. After equilibrium, the mixtures were centrifuged, and concentrations in the supernatant were determined.

Dye sorption experiments with raw materials like bentonite, charcoal, and bare nZVI were also performed. The results showed (fig. 1a) limited removal of dyes with bentonite and bare fresh nZVI. Limited removal in the case of bare nZVI can be attributed to the instantaneous oxide shell generation on its surface. While charcoal has shown complete MB removal but lesser RB removal than synthesized composites.

As reported, organic solvents like- ethanol, isopropanol, acetone etc. can extract the adsorbed dye fractions from the composites [66]. Therefore, initially, to ensure the recovery in ethanol, dye adsorbed charcoal was washed with ethanol (fig. 1b) and checked for dyes concentration in washed solution, results show complete $100 \%$ recovery of RB corresponding to no RB associated peaks in FT-IR spectra of washed charcoal (fig. 1c) while limited MB recovery corresponding to presence of MB associated peaks in FT-IR spectra (fig. 1c) suggesting strong MB interaction with charcoal. Therefore, it can be concluded that if the recovery is $<<100 \%$, and the adsorbent showed dye associated FTIR peaks corresponding to its strong chemisorption. On the other hand, if the recovery is limited $(<<100 \%)$ and dyes associated peaks are not present in FT-IR spectra of washed composite, it can represent the organic degradation of dyes (fig. 1d). Therefore, in our studies, we have performed similar experiments and spectroscopic analysis for various synthesized composites to delineate different dye removal mechanisms. 


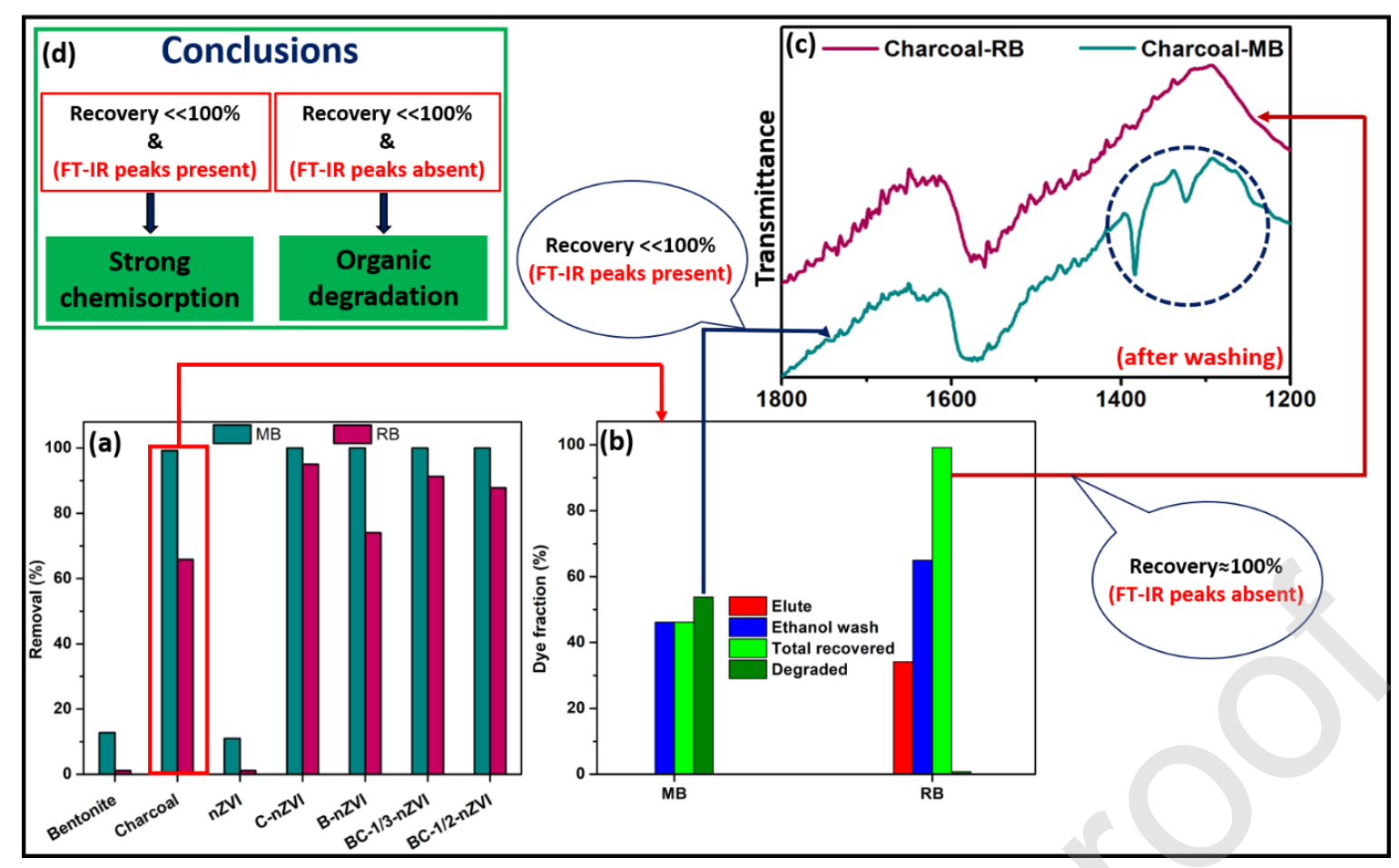

Fig. 1 (a) MB and RB removal \% for different composites and raw materials i.e. bentonite, charcoal and bare nZVI (fresh), (b) dyes fraction recovered in elute and washing from charcoal showing complete RB recovery and limited MB recovery, (c) associated FT-IR spectra of ethanol washed charcoal-dye precipitate and (d) combined conclusion on probable removal mechanisms

For further sorption experiments, $20 \mathrm{mg}$ of adsorbent (m) was added in $20 \mathrm{ml}(\mathrm{V})$ of either DIW ( $\mathrm{pH}=6.4)$ or $\mathrm{SWW}(\mathrm{pH}=7.3)$ solutions with a fixed concentration of $\mathrm{MB}$ or $\mathrm{RB}\left(\mathrm{C}_{0}\right)$ which was $50 \mathrm{mg} / \mathrm{L}$ in case of removal kinetics study and varying concentrations in case of sorption isotherm modeling. The composition of synthetic wastewater [62] is provided in SI (table S1). These reaction mixtures were taken in $50 \mathrm{ml}$ centrifuge tube and shaken at $200 \mathrm{RPM}$ for 6 hours at room temperature $\left(25^{\circ} \mathrm{C}\right)$ in case of isotherm studies and for varying time during removal kinetics studies. After that, solutions were centrifuged, and supernatants were analyzed for residual $\mathrm{MB}$ and $\mathrm{RB}$ concentrations $\left(\mathrm{C}_{\mathrm{e}}\right)$ with $\mathrm{UV}-\mathrm{Vis}$ Spectrophotometer (See calibration curves - fig. S1 and S2).

QA/QC of obtained data was assured by performing controlled and blank experiments in parallel. Controls were having similar experimental parameters excluding the adsorbents while blanks were without adsorbates (MB or $\mathrm{RB}$ ) in the solutions. Removal (\%) and sorption 
capacity $(\mathrm{q})$ which will be $\mathrm{q}_{\mathrm{e}}$ in case of equilibrium sorption experiments and $\mathrm{q}_{\mathrm{t}}$ in removal kinetics studies, were calculated as-

$$
\begin{gathered}
\text { Removal }(\%)=\frac{C_{0}-C_{e}}{C_{0}} \times 100 \% \\
\text { Sorption Capacity }(q)=\left(C_{0}-C_{e}\right) \times \frac{\mathrm{V}}{\mathrm{m}} \mathrm{mg} / \mathrm{g}
\end{gathered}
$$

Total degraded which includes irreversibly attached or chemisorbed fraction was calculated as-

$$
\text { Degraded dye fraction }(\%)=\frac{C_{0}-C_{e}-C_{w}-C_{e t h}}{C_{0}} \times 100 \%
$$

Where

$\mathrm{C}_{0}=$ initial dye concentration

$\mathrm{C}_{\mathrm{e}}=$ concentration in supernatant (elute)

$\mathrm{C}_{\mathrm{w}}=$ concentration in water wash supernatant

$\mathrm{C}_{\mathrm{eth}}=$ concentration in ethanol wash supernatant 


\section{Results and Discussion}

\subsection{Morphological characterization}

Obtained SEM images of raw bentonite clay and charcoal along with micrographs of various synthesized nZVI nanocomposites are shown in figure-S3 a-f. Clay showed flaky nature while charcoal was granular in shape but contains abundant tiny pores (Fig. S3 a,b). nZVI particles were of spherical shape and can be seen dispersed on all supporting materials (Fig. S3 c-f).

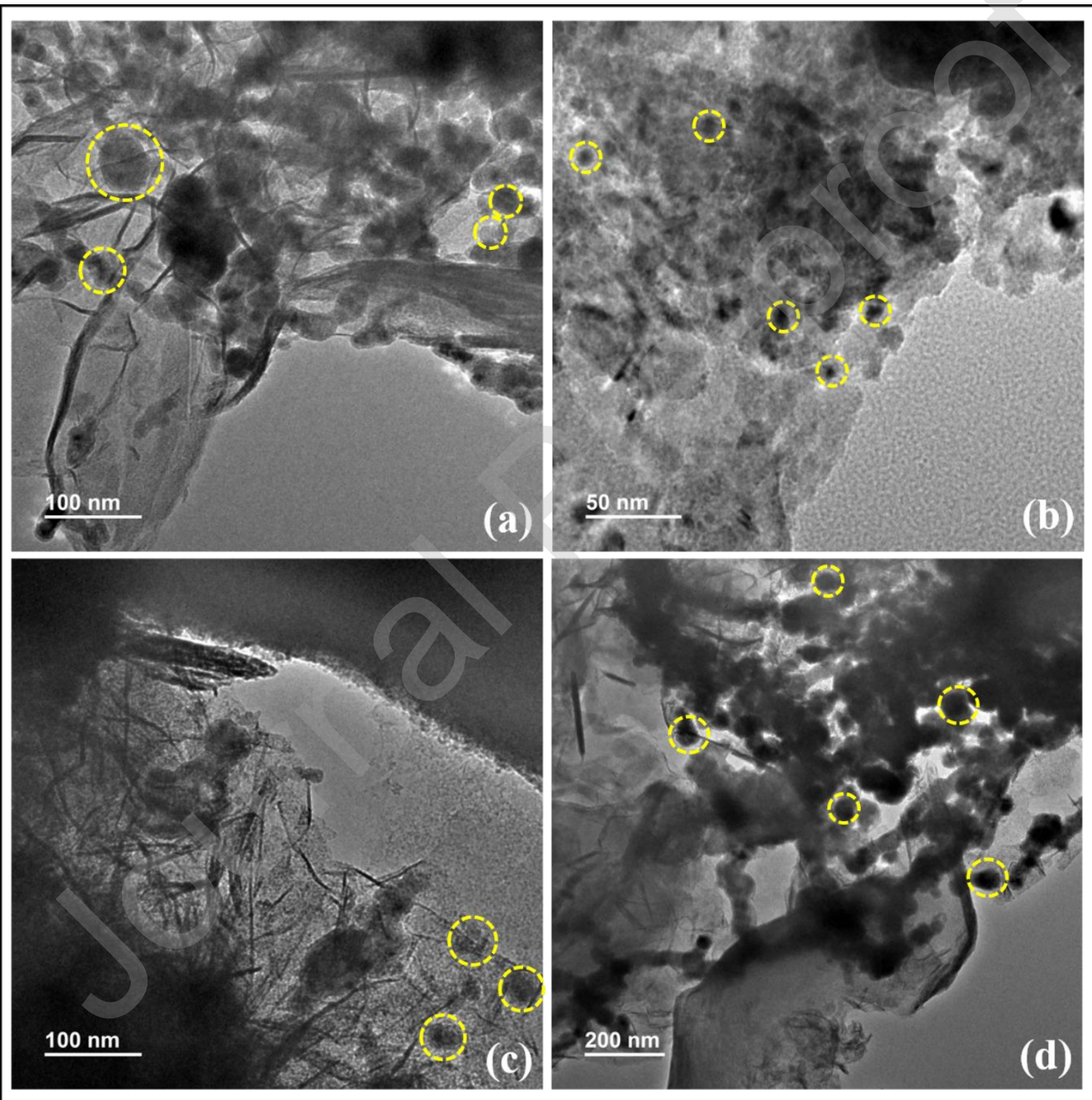

Fig. 2 HRTEM images of (a) B-nZVI, (b) C-nZVI, (c) BC-1/2-nZVI and (d) BC-1/3-nZVI showing supported spherical nZVI particles 
HRTEM images of various supported nZVI composites are provided in fig. 2 (a-d) where nZVI on charcoal show smaller size $(<10 \mathrm{~nm})$ than on bentonite $(>20 \mathrm{~nm})$ (fig. $2 \mathrm{a}, \mathrm{b})$. It might be due to the high rate of nucleation within the pores of charcoal and less growth of nZVI particles during synthesis [67].

Iron particles can be seen supported and dispersed combinedly on clay flakes and charcoal granules in the case of BC-1/2-nZVI and BC-1/3-nZVI (fig. 2 c,d) with $20 \mathrm{~nm}$-sized spheres of iron. The well dispersed nZVI particles can be observed on different composite surfaces.

\subsection{Crystallinity and surface characterization}

To confirm the effect of long-term storage on oxidation of nZVI, powder XRD data were obtained for all fresh and aged nanocomposites (Fig. 3a), and results show that bare fresh nZVI particles show intense iron oxide peaks near $30^{\circ}$ and $35^{\circ}$ along with $44.8^{0}$ nZVI peaks. Fresh nZVI composites show the absence of iron oxide peak, while the generation of $35^{\circ}$ iron oxide peak was observed in all aged composites. The intensity of $35^{\circ}$ iron-oxide peak in aged composites was comparatively very less than fresh bare nZVI, suggesting a generation of a very thin surface oxide layer. The maximum decrease in $\mathrm{Fe}^{0}$ peak was observed in the case of C-nZVI and BC-1/2-nZVI. However, the presence of $44.8^{0} \mathrm{nZVI}$ peak with significant intensity in B-nZVI and BC-1/3-nZVI aged composites suggest that these surfaces were most successful in preventing iron oxidation.

Further, FT-IR spectra were obtained to confirm the successful synthesis of various composites and results in fig. $3 \mathrm{~b}$ shows that porous charcoal doesn't have any functional groups on the surface, while clay shows distinct peaks at $1044 \mathrm{~cm}^{-1} \mathrm{Si}-\mathrm{O}$ bending vibrations peak, which was also present in bentonite and various BC-nZVI composites along with antisymmetric Si-O-Si stretching vibrations around $797 \mathrm{~cm}^{-1}$ visible in bentonite spectra [68]. $1632 \mathrm{~cm}^{-1}$ absorption 
peak was due to $\mathrm{O}-\mathrm{H}$ vibration reflecting crystal water of bentonite lattice, also present in $\mathrm{BC}$ nZVI composites [69].
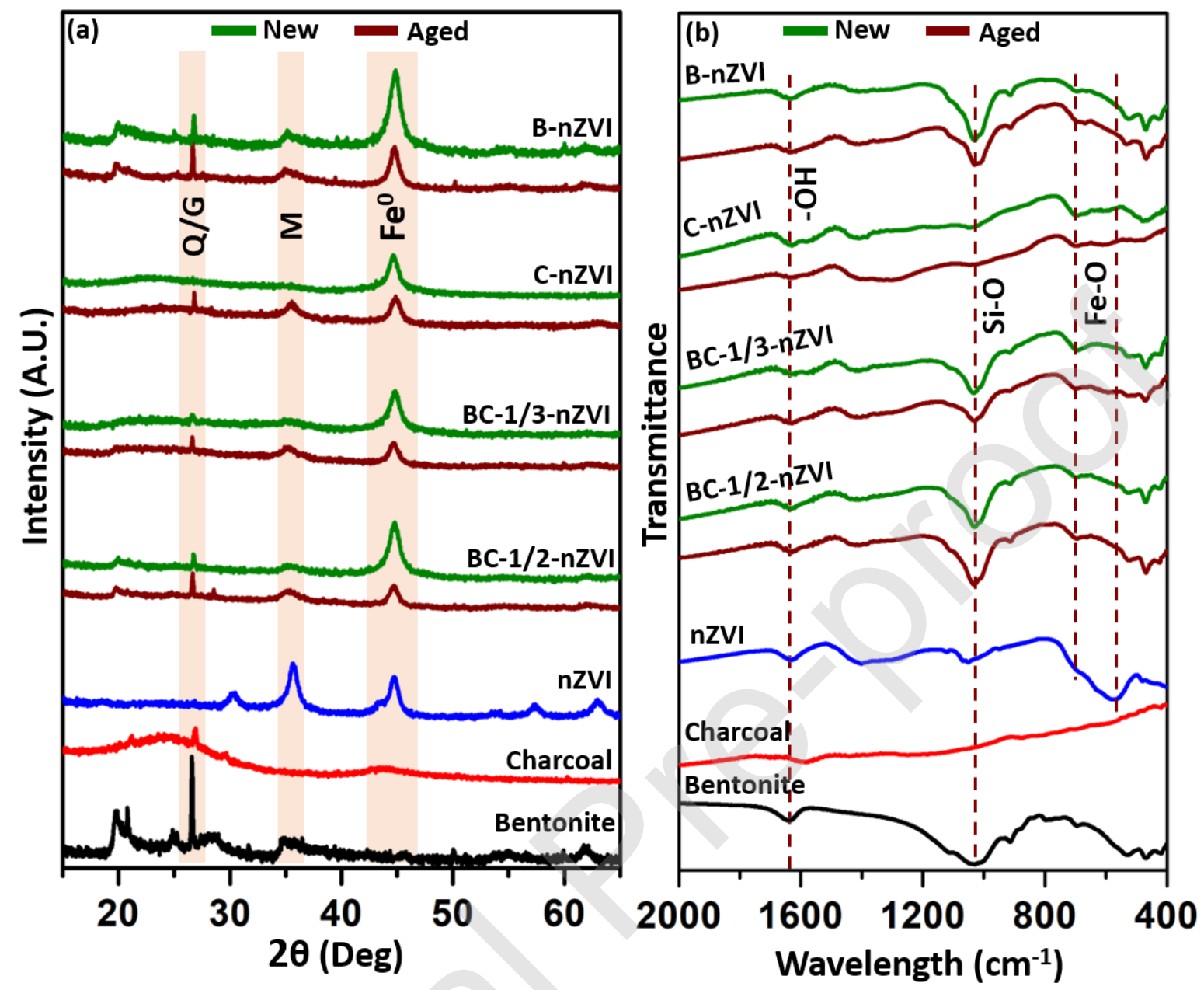

Fig. 3 (a) pXRD spectra of various raw materials with new and aged composites $(Q=$ quartz, $\mathrm{G}=$ graphite and $\mathrm{M}=$ magnetite) (b) FT-IR spectra showing functional groups on various composites and raw materials (fresh)

Less intensity of Si-O band peaks in BC-nZVI than B-nZVI with Fe-O stretching of almost equal intensity supports the presence of charcoal with bentonite in BC-nZVI composites. FTIR spectra of bare nZVI show the major band at $570 \mathrm{~cm}^{-1}$ due to the symmetric Fe-O stretch of magnetite $\left(\mathrm{Fe}_{3} \mathrm{O}_{4}\right)$ which is not present in both new and aged nanocomposites, while the band 
at $670 \mathrm{~cm}^{-1}$ is due to the symmetric Fe-O stretch of goethite $(\alpha-\mathrm{FeOOH})$ is present in both fresh and aged composites [70].

Zeta potential as a function of solution $\mathrm{pH}$ was obtained for various supported nZVI composites to confirm their charge and suspension stability and results in fig. S4 shows that in environmental relevant $\mathrm{pH}$ range i.e. $\mathrm{pH}=4-9$, zeta potential is negative. Furthermore, the zeta potential of nanocomposites in wastewater was negative $(<-20 \mathrm{mV})$ which suggests stability of the suspension and their ability to electrostatically attract both cationic and zwitterionic dyes (Table- S2).

\subsection{Sorption, recovery and degradation of dyes}

To confirm the applicability of the composites in the removal of both MB and RB dyes, sorption experiments were performed. Moreover, the reversibility of the sorption, dyes recovery and degradation was evaluated by washing the reaction precipitate in water and ethanol sequentially. Results in fig. 4 (a) show that all the composites were able to remove MB completely. Water and ethanol washing of MB-nanocomposite reaction precipitate results in no significant release of methylene blue, confirming either its strong interaction with the composites or its transformation to other organic compounds.

MB sorption on nanocomposites was duly confirmed through FT-IR spectra of the reaction precipitate (fig. $4 \mathrm{c}-\mathrm{f}$ ) which shows that in case of MB, C-N stretching vibrations at 1323 and $1384 \mathrm{~cm}^{-1}$ and absorption peak at $1588 \mathrm{~cm}^{-1}$ (aromatic rings) are present in all reaction precipitates confirming adsorption of MB onto the composites. Further, no release of MB in the elute and even after water washing with $<1.5 \mathrm{mg} / \mathrm{L}$ release after ethanol washing, confirms $>95 \%$ degradation or irreversible adsorption of MB by the composites (fig. 4a). Presence of MB associated peaks even after ethanol washing (fig. 4 c-d) in the reaction precipitates of BnZVI and BC-1/2-nZVI confirms irreversible adsorption which can be attributed to the 
reduction of $\mathrm{MB}$ in leuco-MB and its co-precipitation with oxidized iron on the surface of composites [71].

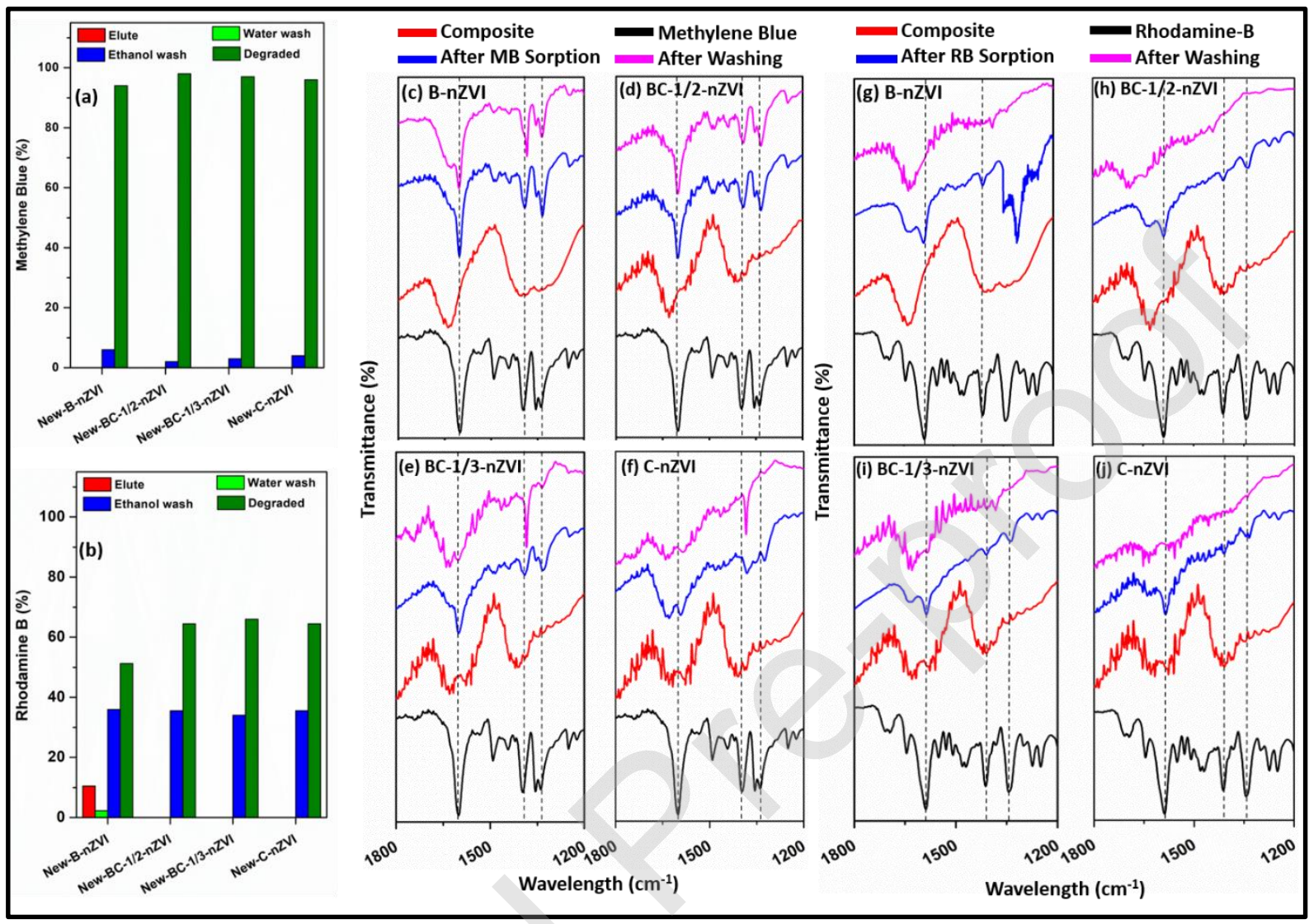

Fig. 4 (a) MB and (b) RB \% in the elute (red), after water (green) and ethanol (blue) washing and calculated total degraded dye fraction (olive), (c-j) FTIR spectra of different composites before and after dyes interaction and after ethanol washing for MB (c-f) and RB (g-j)

In case of higher charcoal concentration in composites i.e. BC-1/3-nZVI and C-nZVI, after ethanol washing, MB associated peaks disappeared (fig. 4 e-f) which suggests its organic degradation probably through Fenton oxidation [72-74]. However, in the case of higher clay concentration, reduction to LMB was probably more dominant [75]. Results suggest that removal of $\mathrm{MB}$ with all composites was probably a combination of sorption, reduction [76] and organic degradation [72] at the interface. Released fraction during ethanol washing can be either the exchanged $\mathrm{MB}$ within clay layers or retained $\mathrm{MB}$ in charcoal pores. Irreversible 
attachment of leuco-MB was also assured through the UV-Vis spectra of the supernatant obtained from ethanol washing.

Bar diagram in fig. $4 \mathrm{~b}$ shows the complete removal of $\mathrm{RB}$ on different composites. FT-IR spectra of RB-nanocomposite reaction precipitate (fig. $4 \mathrm{~g}-\mathrm{j}$ ) exhibit aromatic $\mathrm{C}-\mathrm{C}$ stretching $\left(1345 \mathrm{~cm}^{-1}\right)$ and $\mathrm{C}-\mathrm{O}$ stretching $\left(1250 \mathrm{~cm}^{-1}\right)$, respectively. $1590 \mathrm{~cm}^{-1}$ sharp absorption band can be assigned to $\mathrm{COO}-$ functional group's asymmetric stretching, and the occurrence of $1465 \mathrm{~cm}^{-1}$ band can be attributed to symmetric stretching of the same group [77]. Results support the interaction and adsorption of RB on different composites, although the intensity of the characteristic peaks of RB at the composite surface appears rather small. To confirm the reversibility of RB sorption, recovery experiments were done (fig. 4 b)as described in the case of MB. Results show that B-nZVI releases a smaller fraction of RB in water washing. The recovered fraction of $\mathrm{RB}$ was the non-degraded proportion in the adsorbent. This might be a combined contribution of retention of RB in charcoal pores, adsorption of RB on nZVI through electrostatic attraction, cation exchange in bentonite, $\pi-\pi$ interaction between the clay surface and organic functional groups and binding of the nitrogen atom with surface metal either directly or through hydrogen bonding [78].

To confirm that whether the non-recovered fraction of RB was strongly adsorbed or degraded, FT-IR spectra of ethanol washed composites were obtained (fig. 4 g-j), which shows the disappearance of the RB associated peaks from the composites after washing, confirming dye degradation. Further analysis of FT-IR spectra (fig. S13- S16) shows the generation of $570 \mathrm{~cm}^{-}$ ${ }^{1}$ peak (Fe-O stretching due to magnetite) in all fresh nZVI composites in DIW after sorption of dyes [70]. RB degraded proportion for different C-containing composites was similar (BC1/3-nZVI (66\%); C-nZVI (64.5\%); BC-1/2-nZVI (64.5\%)), and only slightly smaller for BnZVI (51.2\%). The organic degradation of RB may be attributed to the Fenton oxidation by nZVI (fig. 5) in the presence of dissolved oxygen in water [32]. A schematic diagram 
representing the different probable dye degradation mechanisms for $\mathrm{RB}$ and $\mathrm{MB}$ is provided in fig. 5 .

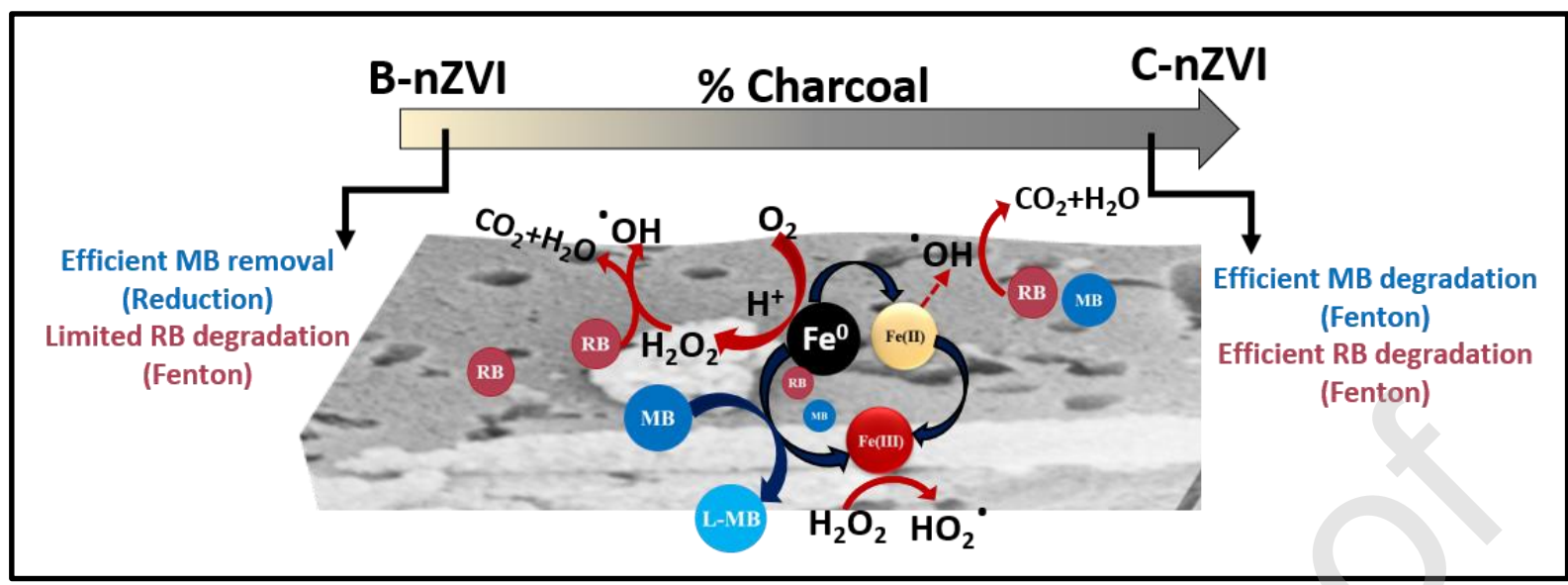

Fig. 5 Schematic diagram showing probable mechanisms for RB and MB degradation using surface supported nZVI nanocomposites

\subsection{Impact of aging on dye removal}

After ensuring the applicability of different nanocomposites in the removal of RB and $\mathrm{MB}$ and delineating various probable removal mechanisms, it was essential to understand the impact of their long-term storage on dye sorption capacities. Therefore, the synthesized composites were stored for 300 days in an open-air environment and comparatively evaluated with fresh nanocomposites for the effect of aging on both removal kinetics and maximum sorption capacities.

\subsubsection{Removal kinetics}

To determine, how fast these synthesized composites can remove the dyes from aqueous solution and, the impact of aging on removal kinetics for MB and RB, $20 \mathrm{mg}$ of adsorbent was added to $20 \mathrm{ml} \mathrm{RB}$ or $\mathrm{MB}$ solution of $50 \mathrm{mg} / \mathrm{L}$ concentration and shaken for varying time before filtration and analysis. 
Obtained results, shown in fig. $6(a, b)$, confirm that in case of MB, all fresh and aged composite show complete removal within 2 hours. Whereas, the behavior of composites was different in the presence of RB (fig. 6 c-d), where a significant difference in their RB removal capacity was observed. Except for BC-1/3-nZVI, all composites show a decrease in RB removal after aging and B-nZVI shows the least RB removal capacity of nearly $10 \mathrm{mg} / \mathrm{g}$ after aging.

Removal of RB and MB on different composites was controlled by various interfacial chemical processes along with sorption, as shown earlier, which was duly confirmed by fitting the data with the pseudo $2^{\text {nd }}$ order kinetic model for MB (fig. S7 a-h and table-S3) and RB (fig. S8 a-h and table S4). Data modeling with the pseudo $1^{\text {st }}$ order equation provided rather an inadequate description of the data, i.e., mismatch of modeled sorption capacities with experimental data (preliminary test not shown).

Fig. 6e shows the pseudo $2^{\text {nd }}$ order rate constants obtained for fresh and aged composites for MB. In the case of fresh composites, for B-nZVI and C-nZVI, removal rates are nearly equal (0.058 and $0.049 \mathrm{~g} / \mathrm{mg} . \mathrm{min})$ and highest, whereas BC-1/3-nZVI and BC-1/2-nZVI composites show the slower removal (0.012 and 0.009 g/mg.min). Aging had only little effect on MB removal rate of BC-1/3-nZVI but showed an increase for B-nZVI and a decrease for others. This can be attributed to a larger immobilization of MB by aged B-nZVI, according to intense MB associated peaks in obtained IR data (fig. 4a). A slight decrease in MB sorption capacity was due to surface passivation of aged C-nZVI, as confirmed from pXRD spectra in fig. $3 \mathrm{a}$. Nevertheless, removal rates for aged and fresh composites remained rather high, signifying minimal impact of aging on MB removal. 


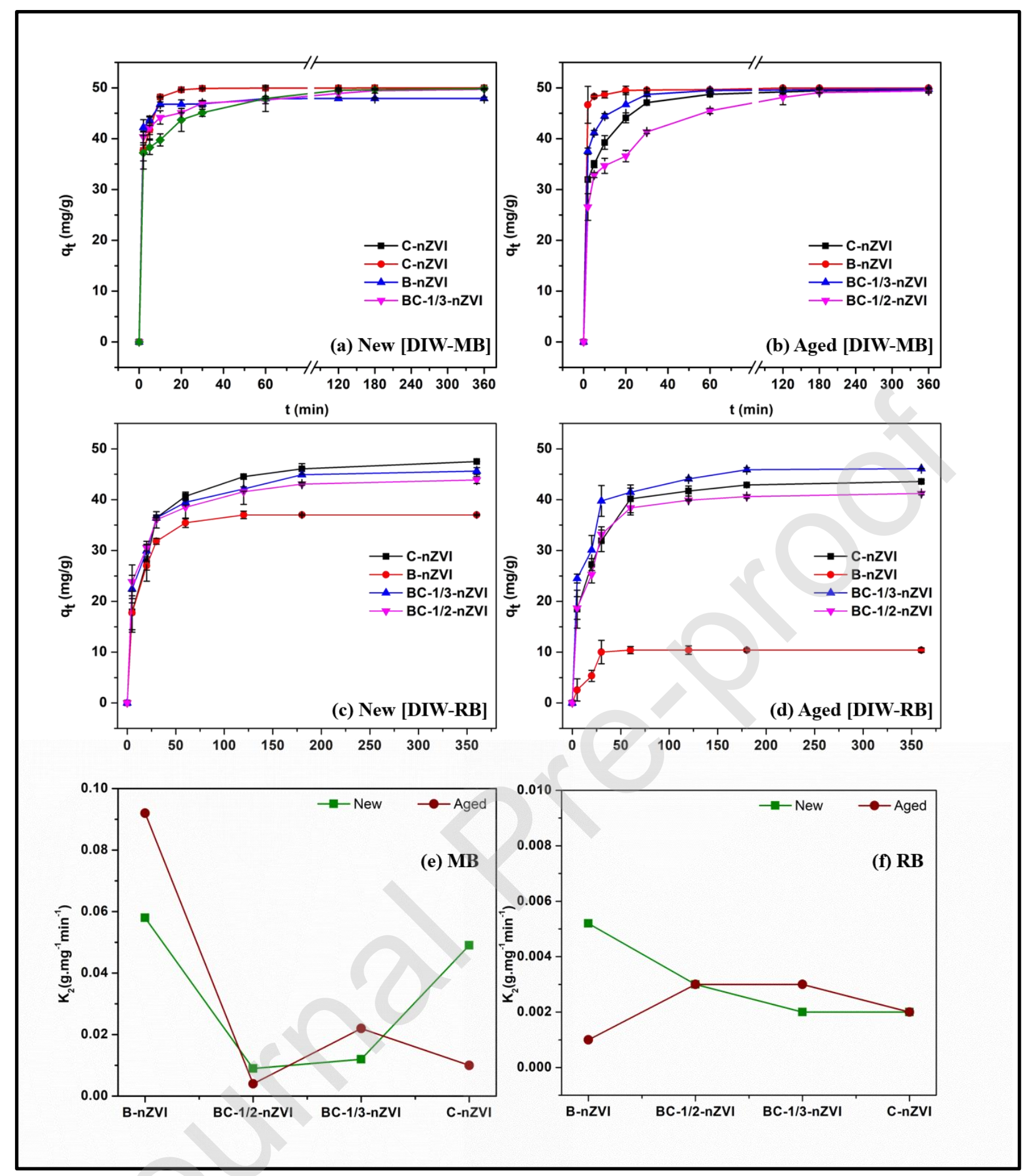

Fig. 6 Effect of nanocomposites aging on removal kinetics for MB (a, b) and RB (c, d) in DIW $(\mathrm{pH}=6.4)$ and pseudo $2^{\text {nd }}$ order rate constants for MB (e) and $\mathrm{RB}(\mathrm{f})$

In the case of RB (fig. 6f), the removal rate was slower than MB for all composites and, ranged between 0.001-0.005 g/mg.min even after aging. B-nZVI shows faster (0.005 g/mg.min) but comparatively less removal $(37 \mathrm{mg} / \mathrm{g})$ than all composites which drastically decreased to 10 
$\mathrm{mg} / \mathrm{g}$ with a slower rate $(0.001 \mathrm{~g} / \mathrm{mg} \cdot \mathrm{min})$ after aging. In the case of all other composites, aging imposed minimal impact on both removal rate and capacity.

IPD modelling was also performed to confirm rate-limiting step for different composites and results suggest that in case of MB (fig. S9 a-h), all fresh and aged composites show three linear segments attributing to bulk transport or film diffusion followed by intra-particle mesopores, macropores and micropores diffusion and final equilibrium stage, revealing that IPD is not the only rate-limiting step in the reaction. While in the case of RB (fig. S10 a-h), B-nZVI show IPD as a rate-limiting step because two linear segments were found, and the curve is starting from the origin, suggesting slow removal. Bulk transport or film diffusion, which is the fastest step in the reaction, was comparatively more dominant in the case of MB than RB. Obtained parameters for IPD model were also provided in table- S3 and S4. Since earlier experiments confirmed different removal mechanisms for MB and RB therefore other than IPD, after bulk transport, the second step can be a combined contribution of electron transfer and reduction or free radical generation and degradation before achieving final equilibrium. Easier electron transfer and $\mathrm{MB}$ reduction than a free radical generation and $\mathrm{RB}$ degradation can be one probable explanation for slower RB removal.

\subsubsection{Removal capacity}

After evaluating the effect of composites aging on the kinetics of dyes removal, it was essential to check the effect of an increase in the concentration of dyes on the removal efficiency of different composites and simultaneously to compare maximum dyes sorption capacities of different composites before and after aging. Therefore, $\mathrm{MB}$ and $\mathrm{RB}$ concentrations were increased in the solution by keeping the adsorbent amount and volume constant i.e. $20 \mathrm{mg}$ and $20 \mathrm{ml}$, respectively. Results in the figure- 6 show that the removal efficiency of all composites was higher for MB than of RB. In the case of MB (fig. 7 a,b), the removal capacity of C-nZVI and $\mathrm{BC}-1 / 3-n Z V I$ was higher than of BC-1/2-nZVI and B-nZVI. No significant change was 
observed for the removal capacity of BC-1/3-nZVI while a decrease was obtained for both BC1/2-nZVI and B-nZVI after aging.

While, in case of RB (fig. 7 c,d), all fresh composites have shown equal removal except BnZVI, which showed comparatively less but efficient removal of RB. Like MB, a similar impact of aging was observed in the case of RB except for B-nZVI for which removal decreased drastically after aging. Interestingly, the removal capacity of BC-1/3-nZVI was increased while the remaining two composites had faced a slight decrease in RB removal capacity.

FT-IR spectra of various reaction precipitates (fig. S13- S16) show the generation of $570 \mathrm{~cm}^{-1}$ peak (Fe-O stretching due to magnetite) in all fresh nZVI composites in DIW after sorption of dyes [70]. While in the case of aged composites, $532 \mathrm{~cm}^{-1}$ (due to $\gamma$-FeOOH) peak was dominant [79]. The increased surface oxide layer of $\gamma$-FeOOH might be the reason for decreased $\mathrm{MB}$ and $\mathrm{RB}$ removal after aging.

As the removal of dyes was a mixture of different mechanisms, to interpret the nature of sorption, data was fitted in various non-linear isotherm models, i.e., Langmuir, Freundlich, and Sip models (Fig. S11 and S12). Details including equations, data plots, and parameters obtained have been provided in section-3 of supplementary information.

Obtained parameters ( $\mathrm{k}$ and $\mathrm{n}$ ) from Freundlich isotherm for both the dyes have been plotted in fig. $7(e, f)$. 'n' values help in comparing the heterogeneous nature of sorption which can also support the initial spectroscopic observations, indicating multiple dyes removal mechanisms. Whereas, $\mathrm{K}_{\mathrm{F}}$ values helps in understanding the partitioning of contaminants between solution and adsorbents. At low MB concentration, complete removal was observed, so only data at high initial $[\mathrm{MB}]$ could be used for fitting. Because no plateau could be observed within the range of experimental conditions investigated, data fit comparatively well with the Freundlich model (table- S5). As suspected, interfacial mechanisms are highly heterogeneous 
[80], which leads to low $n$ values for all composites $(0.04<\mathrm{n}<0.11)$. Freundlich constant $\left(\mathrm{K}_{\mathrm{F}}\right)$ clearly shows a slight increase in the partitioning of MB for BC-1/3-nZVI after aging while a decrease for BC-1/2-nZVI and C-nZVI. However, removal capacities were in the range of 65$85 \mathrm{mg} / \mathrm{g}$ for all the composites, suggesting efficient MB removal and minimal impact of aging.

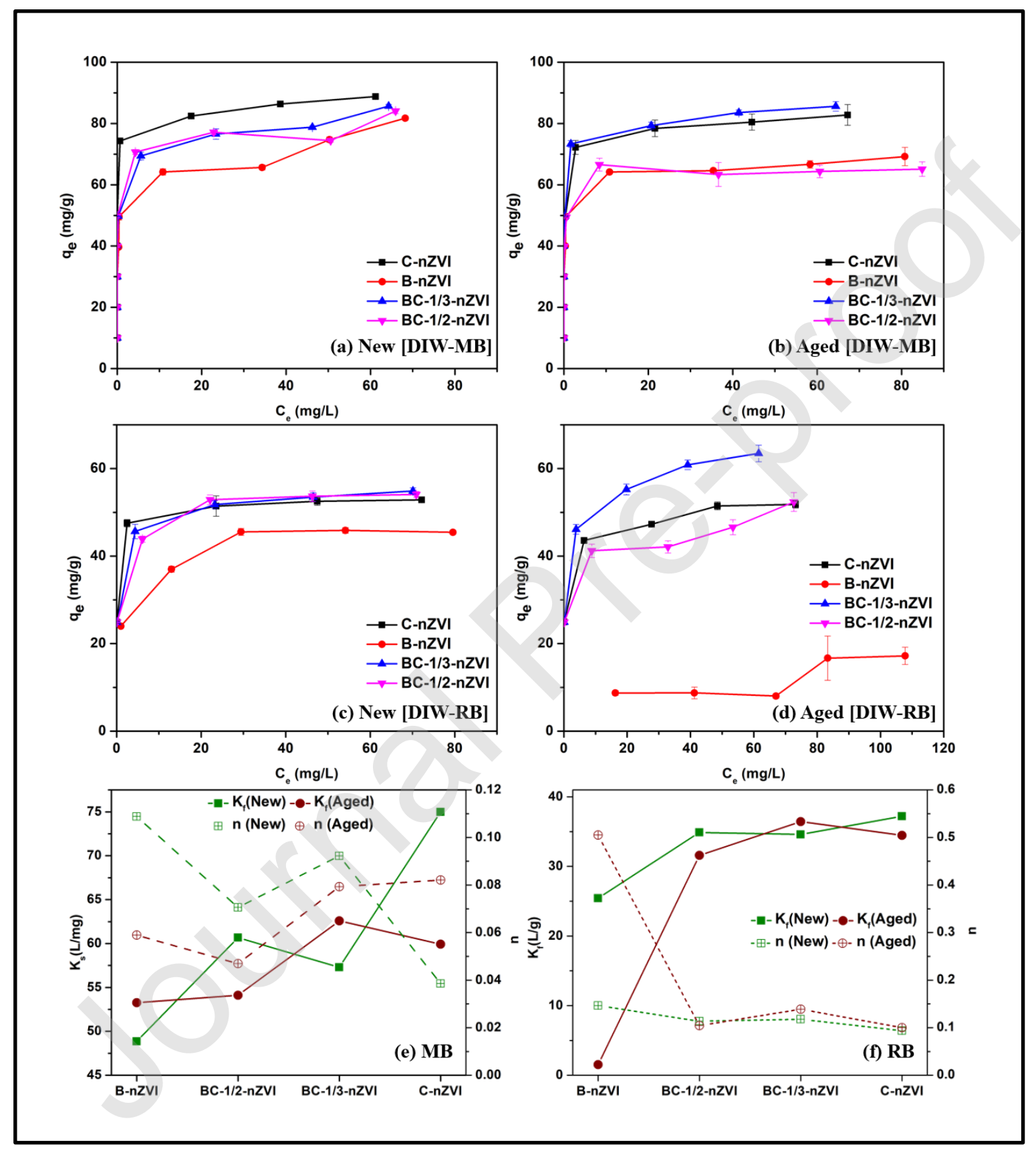

Fig. 7 Effect of nanocomposites aging on their MB (a, b) and RB (c, d) sorption capacities in DIW ( $\mathrm{pH}=6.4$ ) and best-fitted isotherm parameters i.e. Freundlich for MB (e) and RB (f) 
As for MB, RB also experiences a mixture of different mechanisms at the composite-water interface, which requires a Freundlich-type equation to predict its removal. However, in contrast with MB, a plateau was observed for all fresh composites for RB and except B-nZVI, the plateau was not observed after aging. Therefore, data (table- S6) shows a quite well fit with Sip's isotherm (a combination of Langmuir and Freundlich models).

Obtained Freundlich parameters $\left(\mathrm{K}_{\mathrm{F}}\right.$ and $\mathrm{n}$ ) have been plotted in fig. $7 \mathrm{f}$ which clearly shows a decrease in both $\mathrm{K}$ and $\mathrm{n}$ values after aging which was minimal for BC-1/3-nZVI. $\mathrm{K}_{\mathrm{F}}$ values were higher for $\mathrm{MB}$ than for $\mathrm{RB}$, suggesting more partitioning of $\mathrm{MB}$ on the adsorbent. For $\mathrm{RB}$, obtained $\mathrm{n}$ values for all composites except aged B-nZVI, were in the range of 0.09 to 0.5 which confirms the non-ideal behaviour of sorption supporting earlier predicted different chemisorption mechanisms. However, a slight increase in RB sorption capacity was also observed for BC-1/3-nZVI after aging. Fresh B-nZVI showed minimal removal capacity (49.9 $\mathrm{mg} / \mathrm{g}$ ) which drastically decreases to $<20 \mathrm{mg} / \mathrm{g}$ after aging. However, for all other composites, RB sorption capacity was in the range of $50-75 \mathrm{mg} / \mathrm{g}$, suggesting efficient removal of RB with minimal impact of aging.

\subsection{Impact of aging on removal in wastewater}

After assuring the impact of the aging of nanocomposites on the removal of MB and RB dyes and delineating various probable removal mechanisms, the next step in assuring real environment applications was to check the removal kinetics and capacity in wastewater and impact of aging on dye removal as well. For that, all batch experimental parameters were similar except the solution used in reaction was synthetic wastewater.

Composites were evaluated for both effect of time on dyes removal (section-1 of supplementary information) i.e. removal kinetics (fig. S5) and dyes concentration (fig. S6). Similar to DIW, kinetic and isotherm modelling were performed ( and obtained parameters were plotted in fig. 8 for best-fitted models similar to DIW. Masked data in fig. 8, correspond to values obtained 
in DI water. Results in fig. S5 clearly shows that in the case of MB, compared to DIW, removal of MB in SWW was faster and complete removal was achieved within 1 hour even after aging. Plots for pseudo $2^{\text {nd }}$ order rate constants (fig. 8 a,b) also support that removal in SWW was faster and an increase in rate also observed after aging of the composites. Wastewater was a complex mixture of various dissolved ions and organic matter therefore, the probable explanation can be the generation of new MB binding sites on the composite in SWW or faster nZVI oxidation, resulting in faster electron transfer and MB reduction [81]. However, in the case of RB, removal was comparatively less in SWW for all the composites attributed to higher pH i.e. 7.3. Removal decreased further after aging suggesting limited radical formation and organic degradation due to surface coverage by dissolved organic matter and other ions [82]. FT-IR analysis in fig. S13-S16 show that in contrast to DIW, $570 \mathrm{~cm}^{-1} \mathrm{Fe}-\mathrm{O}$ stretching of magnetite was not observed in SWW. Interestingly, both fresh and aged B-nZVI show no removal of RB in SWW. Effect of aging on C-nZVI and BC-1/3-nZVI was found to be minimal. 


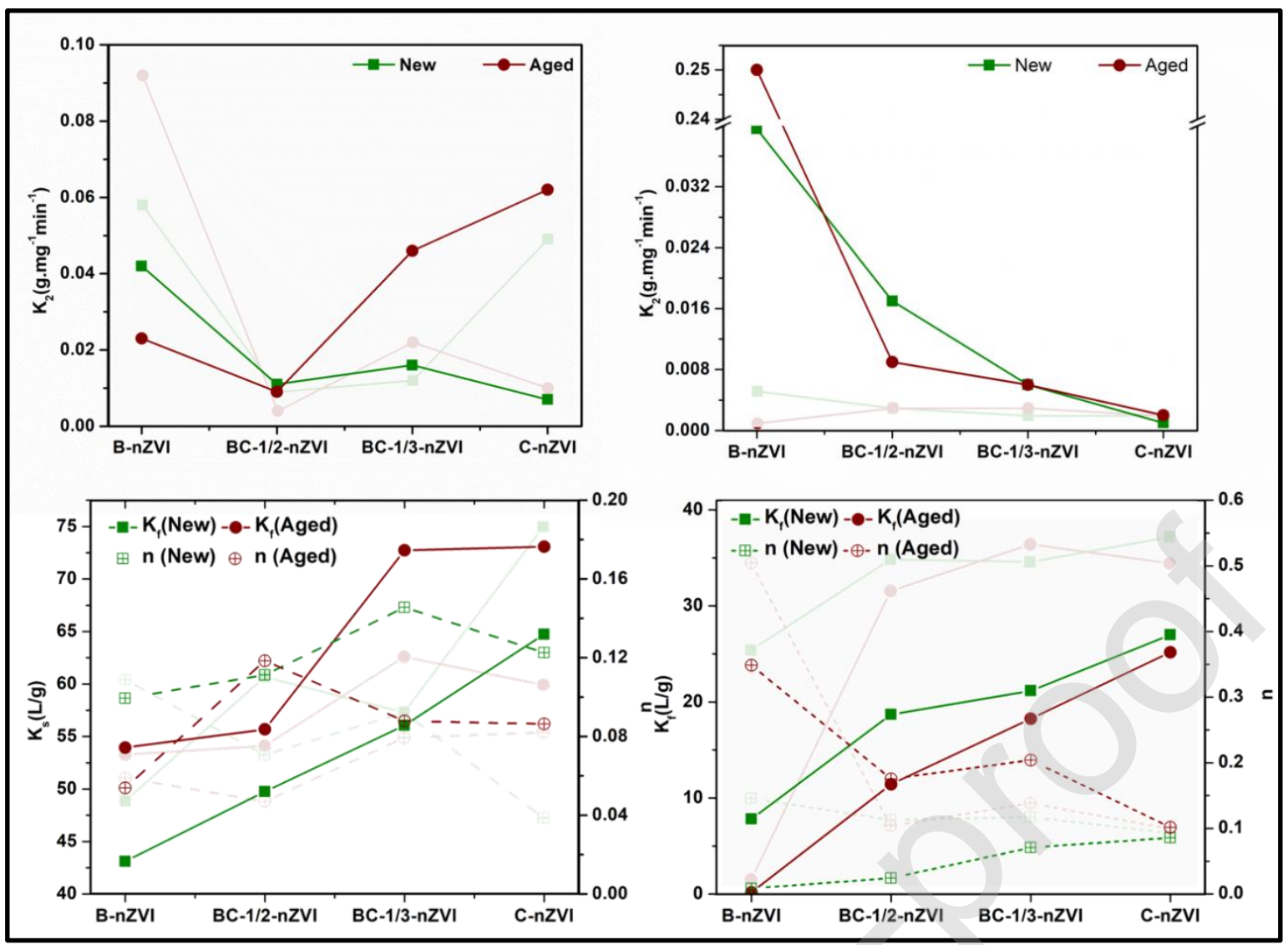

Fig. 8 Pseudo $2^{\text {nd }}$ order rate constants for MB (a) and RB (b) and best-fitted isotherm parameters i.e. Freundlich for MB (c) and RB (d) for different composites in wastewater (notemasked data in every plot corresponds to values obtained in DIW)

Increasing MB concentrations resulted in higher removal capacity of composites compared to DIW, except aged-B-nZVI, the plateau was not obtained suggesting Freundlich like behaviour and heterogeneous nature of sorption with $n$ values ranging between 0.05 to 0.18 . $\mathrm{K}_{\mathrm{F}}$ values were higher for all aged composites (fig. 8c), suggesting higher partitioning of $\mathrm{MB}$ for the adsorbents. Removal capacities follow the same trend as of DI i.e. BC-1/3-nZVI and C-nZVI have shown similar removal capacities which is comparatively higher than BC-1/2-nZVI with least removal with B-nZVI. However, both BC-1/3-nZVI and C-nZVI shows the highest removal in wastewater i.e. $>100 \mathrm{mg} / \mathrm{g}$ for methylene blue. However, in the case of RB (fig. 8d), completely different behaviour of composites was observed in wastewater where removal capacity was decreased in comparison to DIW with lower partitioning of RB to the adsorbent 
as compared to $\mathrm{MB}$ for all the composites. A slight decrease in RB sorption capacity was obtained for BC-1/3-nZVI and C-nZVI, while a drastic fall was observed for B-nZVI i.e. 49.9 $\mathrm{mg} / \mathrm{g}$ in DIW to almost no removal in SWW. The most probable explanation for this behaviour can be obtained from earlier described removal mechanisms, suggests competitive site binding [50] and limited free radical generation in complex wastewater resulting in limited RB sorption and degradation. However, for both fresh and aged BC-1/3-nZVI and C-nZVI, removal capacities were in the range of $35-50 \mathrm{mg} / \mathrm{g}$, showing efficient $\mathrm{RB}$ removal in wastewater. Table S7 in supplementary information shows different explored adsorbents and their RB/MB sorption capacities, suggesting all $\mathrm{B} / \mathrm{C} / \mathrm{BC}$ supported nZVI composites as efficient dye adsorbents.

\section{Conclusion}

The present study concludes that all layered (bentonite like), porous (charcoal-like) and layered-porous (bentonite-charcoal like) surfaces were efficient in preserving the reactivity of nZVI for dyes even after long-term air exposure. Comparatively, nZVI supported on a combined bentonite-charcoal surface with $\mathrm{B} / \mathrm{C}=1 / 3$, i.e., $\mathrm{BC}-1 / 3-\mathrm{nZVI}$ composite has shown the minimal impact of aging. Both new and aged BC-1/3-nZVI composites have shown complete (100\%) removal of MB and RB. Moreover, non-recovered (or degraded) fractions of dyes were $>95 \%$ and $65 \%$ for $\mathrm{MB}$ and $\mathrm{RB}$, respectively. Limited recovery (35\%) in ethanol washing supported by the absence of RB associated peaks in FT-IR spectra clearly suggest the organic degradation of non-recovered dye fraction.

Results also indicate a surface dependent variation in dye removal mechanisms of nZVI. Composites with porous charcoal enriched (C>50\%) surfaces i.e. BC-1/3-nZVI and C-nZVI, remove dyes dominantly through organic degradation. Whereas, for composites with layered clay-enriched surfaces, i.e. B-nZVI and BC-1/2-nZVI, adsorption, reduction to LMB and its co-precipitation were major MB removal mechanisms with limited and slower RB removal. A 
slight decrease in the RB sorption capacity of nanocomposites can be attributed to the enhanced $\gamma$-FeOOH layer on the nanocomposite surface after aging.

In the presence of complex wastewater like aqueous matrices, a dramatic variation in the behaviour of nanocomposites for dyes was observed. Enhanced MB removal in wastewater can be attributed to the generation of new MB binding sites. Whereas a decrease in RB sorption capacity in wastewater can be due to competitive site binding of other ions, higher solution $\mathrm{pH}$ and limited free radical formation.

Overall, it can be concluded that BC-1/3-nZVI (112.3 mg/g for MB and $58.7 \mathrm{mg} / \mathrm{g}$ for RB) and C-nZVI (109.1 mg/g for MB and $53.2 \mathrm{mg} / \mathrm{g}$ for RB) can be two candidate adsorbents that have good environmental applicability, high efficiency with minimal impact of long-term storage for removal of different dyes.

\section{Novelty Statement}

Redox-sensitive nanoparticles can be the key adsorbents for pollutants due to their electron transferring ability along with the high surface area, but the preservation of their redox state and reactivity is a critical challenge. Scientific advancements suggest that supporting surfaces can maintain their reactivity, however, to what extent and for how long are still unknown. Here, redox-sensitive nZVI particles were supported on four different layered or/and porous surfaces by varying bentonite(B)/charcoal(C) ratio, followed by 300 days of air exposure and then comparatively investigated for dyes removal. 


\section{Credit Author Statement}

Nitin Khandelwal

Ekta Tiwari

Nisha Singh

Remi Marsac

Thorsten Schäfer

Fazel Abdolahpur Monikh

Gopala Krishna Darbha
:Writing- Orignial draft, data curation, investigation,

Visualisation

: Investigation, Data curation, writing-review and editing

: Investigation, Data curation, writing-review and editing

: Supervision, Writing- review and editing

: Supervision, Writing-review and editing

: Data curation, Writing-review and editing

: Writing-review and editing, resources, supervision, project administration, funding acquisition

\section{Declaration of interests}

The authors declare that they have no known competing financial interests or personal relationships that could have appeared to influence the work reported in this paper. 


\section{References}

[1] M. ejder korucu, A. Gurses, Ç. Doğar, S. Sharma, M. Açıkyıldız, Removal of Organic Dyes from Industrial Effluents: An Overview of Physical and Biotechnological Applications, in, 2015, pp. 1-22. [2] E. Forgacs, T. Cserháti, G. Oros, Removal of synthetic dyes from wastewaters: a review, Environ Int, 30 (2004) 953-971.

[3] B. Lellis, C.Z. Fávaro-Polonio, J.A. Pamphile, J.C. Polonio, Effects of textile dyes on health and the environment and bioremediation potential of living organisms, Biotechnology Research and Innovation, 3 (2019) 275-290.

[4] J.A. Kiernan, Dyes and other colorants in microtechnique and biomedical research, Color Technol, 122 (2006) 1-21.

[5] N. Bordoloi, M.D. Dey, R. Mukhopadhyay, R. Kataki, Adsorption of Methylene blue and Rhodamine B by using biochar derived from Pongamia glabra seed cover, Water Sci Technol, 77 (2017) 638-646.

[6] E.R. Nestmann, G.R. Douglas, T.I. Matula, C.E. Grant, D.J. Kowbel, Mutagenic activity of rhodamine dyes and their impurities as detected by mutation induction in Salmonella and DNA damage in Chinese hamster ovary cells, Cancer Res, 39 (1979) 4412-4417.

[7] G. Upendar, S. Dutta, P. Bhattacharya, A. Dutta, Bioremediation of methylene blue dye using Bacillus subtilis MTCC 441, Water Sci Technol, 75 (2017) 1572-1583.

[8] G.D. Menezes, T.A. de Carvalho, W.D. Almeida, E.M. Sussuchi, P.R.A. Viegas, R.H. Marino, Bioremediation potential of filamentous fungi in methylene blue: Solid and liquid culture media, Cienc Agrotec, 41 (2017) 526-532.

[9] H.H. Gan, H.N. Zhang, J.W. Cai, H.X. Jin, K.F. Zhang, Bio-adsorption properties of Rhodamine B from aqueous solution onto natural camphor tree leaf powder, Desalin Water Treat, 57 (2016) 15241-15249.

[10] D. Pathania, S. Sharma, P. Singh, Removal of methylene blue by adsorption onto activated carbon developed from Ficus carica bast, Arab J Chem, 10 (2017) S1445-S1451.

[11] N.N. Marnani, A. Shahbazi, A novel environmental-friendly nanobiocomposite synthesis by EDTA and chitosan functionalized magnetic graphene oxide for high removal of Rhodamine B: Adsorption mechanism and separation property, Chemosphere, 218 (2019) 715-725.

[12] A. Verma, R. Dash, P. Bhunia, A Review on Chemical Coagulation/Flocculation Technologies for Removal of Colour from Textile Wastewaters, J Environ Manage, 93 (2012) 154-168.

[13] A.K.H. Al jibouri, J. Wu, S.R. Upreti, Continuous ozonation of methylene blue in water, Journal of Water Process Engineering, 8 (2015) 142-150.

[14] M.S. Kumar, S.H. Sonawane, A.B. Pandit, Degradation of methylene blue dye in aqueous solution using hydrodynamic cavitation based hybrid advanced oxidation processes, Chemical Engineering and Processing: Process Intensification, 122 (2017) 288-295.

[15] C.P. Bai, X.F. Xiong, W.Q. Gong, D.X. Feng, M. Xian, Z.X. Ge, N.A. Xu, Removal of rhodamine B by ozone-based advanced oxidation process, Desalination, 278 (2011) 84-90.

[16] S.H. Chang, K.S. Wang, H.C. Li, M.Y. Wey, J.D. Chou, Enhancement of Rhodamine B removal by low-cost fly ash sorption with Fenton pre-oxidation, J Hazard Mater, 172 (2009) 1131-1136.

[17] Z. Li, Y. Sun, Y. Yang, Y. Han, T. Wang, J. Chen, D.C.W. Tsang, Comparing biochar- and bentonitesupported Fe-based catalysts for selective degradation of antibiotics: Mechanisms and pathway, Environmental Research, 183 (2020) 109156.

[18] E.S.Z. El-Ashtoukhy, Y.O. Fouad, Liquid-liquid extraction of methylene blue dye from aqueous solutions using sodium dodecylbenzenesulfonate as an extractant, Alex Eng J, 54 (2015) 77-81.

[19] Q. Li, Y. Li, X. Ma, Q. Du, K. Sui, D. Wang, C. Wang, H. Li, Y. Xia, Filtration and adsorption properties of porous calcium alginate membrane for methylene blue removal from water, Chem Eng J, 316 (2017) 623-630. 
[20] S.S. Shenvi, A.M. Isloor, A.F. Ismail, S.J. Shilton, A. Al Ahmed, Humic Acid Based Biopolymeric Membrane for Effective Removal of Methylene Blue and Rhodamine B, Ind Eng Chem Res, 54 (2015) 4965-4975.

[21] S. Bolisetty, M. Peydayesh, R. Mezzenga, Sustainable technologies for water purification from heavy metals: review and analysis, Chem Soc Rev, 48 (2019) 463-487.

[22] G. Crini, E. Lichtfouse, Advantages and disadvantages of techniques used for wastewater treatment, Environ Chem Lett, 17 (2019) 145-155.

[23] R. Tang, C. Dai, C. Li, W. Liu, S. Gao, C. Wang, Removal of Methylene Blue from Aqueous Solution Using Agricultural Residue Walnut Shell: Equilibrium, Kinetic, and Thermodynamic Studies, J ChemNy, 2017 (2017) 10.

[24] M. Rafatullah, O. Sulaiman, R. Hashim, A. Ahmad, Adsorption of methylene blue on low-cost adsorbents: A review, J Hazard Mater, 177 (2010) 70-80.

[25] D. Kailash, P. Dharmendra, V. Anil, Low Cost Adsorbents for Heavy Metal Removal from Wastewater: A Review, Res J Chem Environ, 14 (2010) 100-103.

[26] F.L. Fu, W.J. Han, Z.H. Cheng, B. Tang, Removal of hexavalent chromium from wastewater by acid-washed zero-valent aluminum, Desalin Water Treat, 57 (2016) 5592-5600.

[27] S. Ahmed, J. Brockgreitens, K. Xu, A. Abbas, A Nanoselenium Sponge for Instantaneous Mercury Removal to Undetectable Levels, Adv Funct Mater, 27 (2017) 1606572.

[28] F.S. Fateminia, C. Falamaki, Zero valent nano-sized iron/clinoptilolite modified with zero valent copper for reductive nitrate removal, Process Saf Environ, 91 (2013) 304-310.

[29] K. Gupta, N. Khandelwal, G. Darbha, Removal and recovery of toxic nanosized Cerium Oxide using eco-friendly Iron Oxide Nanoparticles, Front Env Sci Eng, 14 (2020).

[30] W. Thalgaspitiya, S. Suib, Transition metal doped TiO2/ reduced graphene oxide composites for highly efficient dye adsorption, Abstr Pap Am Chem S, 255 (2018).

[31] I. Khan, K. Saeed, I. Khan, Nanoparticles: Properties, applications and toxicities, Arab J Chem, (2017).

[32] W.L. Guo, F.F. Hao, X.X. Yue, Z.H. Liu, Q.Y. Zhang, X.H. Li, J. Wei, Rhodamine B removal using polyaniline-supported zero-valent iron powder in the presence of dissolved oxygen, Environ Prog Sustain, 35 (2016) 48-55.

[33] R. Cheng, X.Y. Xue, G.Q. Li, L. Shi, M. Kang, T. Zhang, Y.P. Liu, X. Zheng, J.L. Wang, Removal of waterborne phage and NO3- in the nZVI/phage/NO3- system: competition effect, Rsc Adv, 7 (2017) 25369-25377.

[34] X. Guan, Y. Sun, H. Qin, J. Li, I.M. Lo, D. He, H. Dong, The limitations of applying zero-valent iron technology in contaminants sequestration and the corresponding countermeasures: the development in zero-valent iron technology in the last two decades (1994-2014), Water Res, 75 (2015) 224-248.

[35] H.J. Zhu, Y.F. Jia, X. Wu, H. Wang, Removal of arsenic from water by supported nano zero-valent iron on activated carbon, J Hazard Mater, 172 (2009) 1591-1596.

[36] Z.H. Diao, X.R. Xu, H. Chen, D. Jiang, Y.X. Yang, L.J. Kong, Y.X. Sun, Y.X. Hu, Q.W. Hao, L. Liu, Simultaneous removal of $\mathrm{Cr}(\mathrm{VI})$ and phenol by persulfate activated with bentonite-supported nanoscale zero-valent iron: Reactivity and mechanism, J Hazard Mater, 316 (2016) 186-193. [37] S.A. Kim, S. Kamala-Kannan, S.G. Oh, M. Cho, S. Bae, B.T. Oh, Simultaneous removal of chromium(VI) and Reactive Black 5 using zeolite supported nano-scale zero-valent iron composite, Environ Earth Sci, 75 (2016).

[38] X.S. Lv, Y.L. Zhang, W.Y. Fu, J.Z. Cao, J. Zhang, H.B. Ma, G.M. Jiang, Zero-valent iron nanoparticles embedded into reduced graphene oxide-alginate beads for efficient chromium (VI) removal, J Colloid Interf Sci, 506 (2017) 633-643.

[39] Y. Sun, I.K.M. Yu, D.C.W. Tsang, X. Cao, D. Lin, L. Wang, N.J.D. Graham, D.S. Alessi, M. Komárek, Y.S. Ok, Y. Feng, X.-D. Li, Multifunctional iron-biochar composites for the removal of potentially toxic elements, inherent cations, and hetero-chloride from hydraulic fracturing wastewater, Environ Int, 124 (2019) 521-532. 
[40] N. Khandelwal, M.P. Behera, J.K. Rajak, G.K. Darbha, Biochar-nZVI nanocomposite: optimization of grain size and $\mathrm{FeO}$ loading, application and removal mechanism of anionic metal species from soft water, hard water and groundwater, Clean Technol Envir, (2020).

[41] L. Peng, P.F. Qin, M. Lei, Q.R. Zeng, H.J. Song, J. Yang, J.H. Shao, B.H. Liao, J.D. Gu, Modifying Fe3O4 nanoparticles with humic acid for removal of Rhodamine B in water, J Hazard Mater, 209 (2012) 193-198.

[42] Z.Y. Liang, Q.J. Wen, X. Wang, F.W. Zhang, Y. Yu, Chemically stable and reusable nano zerovalent iron/graphite-like carbon nitride nanohybrid for efficient photocatalytic treatment of $\mathrm{Cr}(\mathrm{VI})$ and rhodamine B under visible light, Appl Surf Sci, 386 (2016) 451-459.

[43] A.O. Dada, F.A. Adekola, E.O. Odebunmi, A.A. Inyinbor, B.A. Akinyemi, I.D. Adesewa, Kinetics and Thermodynamics of Adsorption of Rhodamine B onto Bentonite Supported Nanoscale Zerovalent Iron Nanocomposite, Journal of Physics: Conference Series, 1299 (2019) 012106. [44] W. Guo, F. Hao, X. Yue, Z. Liu, Q. Zhang, X. Li, J. Wei, Rhodamine B removal using polyanilinesupported zero-valent iron powder in the presence of dissolved oxygen, Environ Prog Sustain, 35 (2015) n/a-n/a.

[45] Z. Li, Y. Sun, Y. Yang, Y. Han, T. Wang, J. Chen, D.C.W. Tsang, Biochar-supported nanoscale zerovalent iron as an efficient catalyst for organic degradation in groundwater, J Hazard Mater, 383 (2020) 121240.

[46] C. Lei, Y. Sun, E. Khan, S.S. Chen, D.C.W. Tsang, N.J.D. Graham, Y.S. Ok, X. Yang, D. Lin, Y. Feng, X.-D. Li, Removal of chlorinated organic solvents from hydraulic fracturing wastewater by bare and entrapped nanoscale zero-valent iron, Chemosphere, 196 (2018) 9-17.

[47] B. Calderon, A. Fullana, Heavy metal release due to aging effect during zero valent iron nanoparticles remediation, Water Res, 83 (2015) 1-9.

[48] H. Dong, F. Zhao, G. Zeng, L. Tang, C. Fan, L. Zhang, Y. Zeng, Q. He, Y. Xie, Y. Wu, Aging study on carboxymethyl cellulose-coated zero-valent iron nanoparticles in water: Chemical transformation and structural evolution, J Hazard Mater, 312 (2016) 234-242.

[49] H. Dong, L. Li, Y. Wang, Q. Ning, B. Wang, G. Zeng, Aging of zero-valent iron-based nanoparticles in aqueous environment and the consequent effects on their reactivity and toxicity, Water Environ Res, 92 (2020) 646-661.

[50] T. Pasinszki, M. Krebsz, Synthesis and Application of Zero-Valent Iron Nanoparticles in Water Treatment, Environmental Remediation, Catalysis, and Their Biological Effects, Nanomaterials (Basel), 10 (2020).

[51] X. Sun, T. Kurokawa, M. Suzuki, M. Takagi, Y. Kawase, Removal of cationic dye methylene blue by zero-valent iron: Effects of $\mathrm{pH}$ and dissolved oxygen on removal mechanisms, J Environ Sci Heal A, 50 (2015) 1057-1071.

[52] Q. Wang, X. Song, S.Y. Tang, L. Yu, Enhanced removal of tetrachloroethylene from aqueous solutions by biodegradation coupled with nZVI modified by layered double hydroxide, Chemosphere, 243 (2020).

[53] X.D. Shi, W.Q. Ruan, J.W. Hu, M.Y. Fan, R.S. Cao, X.H. Wei, Optimizing the Removal of Rhodamine B in Aqueous Solutions by Reduced Graphene Oxide-Supported Nanoscale Zerovalent Iron (nZVI/rGO) Using an Artificial Neural Network-Genetic Algorithm (ANN-GA) (vol 7, pg 134, 2017), Nanomaterials-Basel, 7 (2017).

[54] S. Zhu, S.-H. Ho, X. Huang, D. Wang, F. Yang, L. Wang, C. Wang, X. Cao, F. Ma, Magnetic Nanoscale Zerovalent Iron Assisted Biochar: Interfacial Chemical Behaviors and Heavy Metals Remediation Performance, 2017.

[55] M. Ahmad, A.R.A. Usman, M.I. Rafique, M.I. Al-Wabel, Engineered biochar composites with zeolite, silica, and nano-zerovalent iron for the efficient scavenging of chlortetracycline from aqueous solutions, Environ Sci Pollut R, 26 (2019) 15136-15152.

[56] H. Naderpour, M. Noroozifar, M. Khorasani-Motlagh, Photodegradation of methyl orange catalyzed by nanoscale zerovalent iron particles supported on natural zeolite, J Iran Chem Soc, 10 (2013) 471-479. 
[57] R. S, Advances in Application of Natural Clay and Its Composites in Removal of Biological, Organic, and Inorganic Contaminants from Drinking Water, Adv Mater Sci Eng, 2011 (2011).

[58] T.A. Brady, M. Rostam-Abadi, M.J. Rood, Applications for activated carbons from waste tires: natural gas storage and air pollution control, Gas Sep Purif, 10 (1996) 97-102.

[59] W. Zhang, T. Yu, X. Han, W. Ying, Removal of 2-ClBP from soil-water system using activated carbon supported nanoscale zerovalent iron, Journal of Environmental Sciences, 47 (2016) 143-152. [60] H.B. Gu, H. Lou, D. Ling, B. Xiang, Z.H. Guo, Polystyrene controlled growth of zerovalent nanoiron/magnetite on a sponge-like carbon matrix towards effective $\mathrm{Cr}(\mathrm{VI})$ removal from polluted water, Rsc Adv, 6 (2016) 110134-110145.

[61] N. Khandelwal, N. Singh, E. Tiwari, G.K. Darbha, Novel synthesis of a clay supported amorphous aluminum nanocomposite and its application in removal of hexavalent chromium from aqueous solutions, Rsc Adv, 9 (2019) 11160-11169.

[62] W. Cherdchoo, S. Nithettham, J. Charoenpanich, Removal of $\mathrm{Cr}(\mathrm{VI})$ from synthetic wastewater by adsorption onto coffee ground and mixed waste tea, Chemosphere, 221 (2019) 758-767.

[63] C. Lei, S. Yuqing, D. Tsang, D. Lin, Environmental transformations and ecological effects of ironbased nanoparticles, Environ Pollut, 232 (2017).

[64] M. Stefaniuk, P. Oleszczuk, Y.S. Ok, Review on nano zerovalent iron (nZVI): From synthesis to environmental applications, Chem Eng J, 287 (2016) 618-632.

[65] Y.P. Sun, X.Q. Li, J.S. Cao, W.X. Zhang, H.P. Wang, Characterization of zero-valent iron nanoparticles, Adv Colloid Interfac, 120 (2006) 47-56.

[66] P.-J. Lu, H.-C. Lin, W.-T. Yu, J.-M. Chern, Chemical regeneration of activated carbon used for dye adsorption, J Taiwan Inst Chem E, 42 (2011) 305-311.

[67] N.T.K. Thanh, N. Maclean, S. Mahiddine, Mechanisms of Nucleation and Growth of Nanoparticles in Solution, Chem Rev, 114 (2014) 7610-7630.

[68] C.C. Ding, W.C. Cheng, Z.X. Jin, Y.B. Sun, Plasma synthesis of beta-cyclodextrin/Al(OH)(3) composites as adsorbents for removal of UO22+ from aqueous solutions, J Mol Liq, 207 (2015) 224230.

[69] J. Shao, X. Yu, M. Zhou, X. Cai, C. Yu, Nanoscale Zero-Valent Iron Decorated on Bentonite/Graphene Oxide for Removal of Copper lons from Aqueous Solution, Materials, 11 (2018) 945.

[70] A. Liu, W.-x. Zhang, Fine structural features of nanoscale zero-valent iron characterized by spherical aberration corrected scanning transmission electron microscopy (Cs-STEM), Analyst, 139 (2014) 4512-4518.

[71] A. Hamdy, M.K. Mostafa, M. Nasr, Zero-valent iron nanoparticles for methylene blue removal from aqueous solutions and textile wastewater treatment, with cost estimation, Water Sci Technol, 78 (2018) 367-378.

[72] S. Hu, Y. Wu, H. Yao, J. Wei, S. Zhang, Efficient Removal of Methylene Blue by Fenton-like Reaction using nZVI/GAC Composite as Catalyst, 2015.

[73] B. Yang, Z. Tian, L. Zhang, Y. Guo, S. Yan, Enhanced heterogeneous Fenton degradation of Methylene Blue by nanoscale zero valent iron (nZVI) assembled on magnetic Fe3O4/reduced graphene oxide, J Water Process Eng, 5 (2015) 101-111.

[74] B.G.H. Briton, L. Duclaux, Y. Richardson, K.B. Yao, L. Reinert, Y. Soneda, Effectiveness of the dispersion of iron nanoparticles within micropores and mesopores of activated carbon for Rhodamine B removal in wastewater by the heterogeneous Fenton process, Applied Water Science, 9 (2019) 166.

[75] R.L. Frost, Y. Xi, H. He, Synthesis, characterization of palygorskite supported zero-valent iron and its application for methylene blue adsorption, J Colloid Interf Sci, 341 (2010) 153-161.

[76] P. Yu, H. Yu, Q. Sun, B. Ma, Filter paper supported nZVI for continuous treatment of simulated dyeing wastewater, Sci Rep-Uk, 9 (2019) 11322. 
[77] R. Dukali, I. Radović, D. Stojanović, D. Sevic, V. Radojevic, D. Jocic, R. Aleksic, Electrospinning of laser dye Rhodamine B-doped poly(methyl methacrylate) nanofibers, J Serb Chem Soc, 79 (2014) 867.

[78] Y.F. Fang, A. Zhou, W. Yang, T. Araya, Y.P. Huang, P. Zhao, D. Johnson, J.Z. Wang, Z.J. Ren, Complex Formation via Hydrogen bonding between Rhodamine $B$ and Montmorillonite in Aqueous Solution, Sci Rep-Uk, 8 (2018).

[79] A. Liu, J. Liu, B. Pan, W.-x. Zhang, Formation of lepidocrocite ( $\gamma$-FeOOH) from oxidation of nanoscale zero-valent iron (nZVI) in oxygenated water, Rsc Adv, 4 (2014) 57377-57382.

[80] K.V. Kumar, S. Gadipelli, B. Wood, K.A. Ramisetty, A.A. Stewart, C.A. Howard, D.J.L. Brett, F. Rodriguez-Reinoso, Characterization of the adsorption site energies and heterogeneous surfaces of porous materials, J Mater Chem A, 7 (2019) 10104-10137.

[81] Y. Hua, W. Wang, X. Huang, T. Gu, D. Ding, L. Ling, W.X. Zhang, Effect of bicarbonate on aging and reactivity of nanoscale zerovalent iron (nZVI) toward uranium removal, Chemosphere, 201 (2018) 603-611.

[82] E. GilPavas, S. Correa-Sanchez, D.A. Acosta, Using scrap zero valent iron to replace dissolved iron in the Fenton process for textile wastewater treatment: Optimization and assessment of toxicity and biodegradability, Environ Pollut, 252 (2019) 1709-1718. 